\title{
LA «ECOLOGIZACIÓN» DE LOS DERECHOS FUNDAMENTALES EN EL MARCO DEL CONVENIO EUROPEO DE LOS DERECHOS HUMANOS
}

\author{
David SAN MARTÍN SEGURA \\ BECARIO F.P.I. ÁREA DE FILOSOFÍA DEL DERECHO \\ UNIVERSIDAD DE LA RIOJA
}

\author{
s u m a r i o
}

I. Introducción: el CEDH y las generaciones de los derechos humanos en el contexto de la crisis ecológica. 2. El medio ambiente como bien jurídico. 3. Evolución de la jurisprudencia ambiental del TEDH y la Comisión. 4. Líneas transversales de la protección indirecta del medio ambiente en la jurisprudencia del TEDH y la Comisión: a) Posibles vías para la tutela indirecta del medio a partir de la jurisprudencia ambiental del TEDH y la Comisión. b) Aplicación de las cláusulas de limitación de los derechos fundamentales y el margen de apreciación estatal. c) La tensión entre intereses individuales y colectivos. d) El hipotético reconocimiento del derecho fundamental a un medio ambiente adecuado por el TEDH y la Comisión. 5. Algunas conclusiones sobre la acción del TEDH y la Comisión en relación al medio ambiente: la ecologización de los derechos fundamentales. 6. Bibliografía.

\section{Introducción: el CEDH y las generaciones de los derechos humanos en el contexto de la crisis ecológica.}

El carácter esencialmente histórico o evolutivo de los derechos humanos significa su imposible disociación respecto a las condiciones materiales -sociales y políticas- de cada periodo. Éste es, precisamente, el rasgo que pone de manifiesto el enfoque generacional: cada generación de derechos es consecuencia de una determinada situación humana que la reclamó y la impulsó en un concreto momento histórico. No obstante, este hecho no

${ }^{\mathrm{I}}$ Siguiendo la división clásica en tres generaciones, atendiendo a su origen histórico, los derechos civiles y políticos, nacidos de la Revolución Francesa de 1789 por obra de la ideología liberal burguesa, conforman la primera generación; los derechos socio-económicos y culturales, derivados de las revoluciones proletarias, con la Revolución Rusa de I9I7 como colofón, constituyen la segunda; la tercera, compuesta por derechos de tipo esencialmente colectivo, han encontrado su desarrollo en la segunda mitad del siglo XX, por influencia del avance del industrialismo y la llamada 
significa que cada una de ellas constituyan compartimentos estancos, perfectamente independientes entre sí. Al contrario, la materialización de cada generación, que responde a unas necesidades específicas, revela a su vez una insuficiencia, una nueva necesidad, que es el punto de arranque de la generación sucesiva. Por ese motivo, como advierte Pérez Luño, cada generación no es simplemente otra que la anterior, sino que, en cierto modo, es también la anterior. Cada generación acumula e integra el pasado con cada innovación, con lo que «la historia de los derechos humanos se revela, a la vez, como paradigma y como progreso constante» ${ }^{2}$. Existe, pues, un principio de unidad en el conjunto de los derechos fundamentales, que pone de manifiesto lazos de interrelación, de modo que el efectivo disfrute de cada uno está vinculado, en muchos casos, a la protección de otros derechos.

La llamada «jurisprudencia ambiental» dictada por el Tribunal Europeo de los Derechos Humanos (en adelante TEDH) y la Comisión Europea de los Derechos Humanos (en adelante la Comisión), en aplicación del Convenio Europeo de los Derechos Humanos (en adelante CEDH) supone, precisamente, un esfuerzo interpretativo en favor de una lectura unitaria y, podríamos decir, intergeneracional de los derechos humanos. Significa una actualización, por vía hermenéutica, del CEDH con el objetivo de preservar la propia eficacia de los derechos contenidos en el Convenio. Ello, desde la consideración de que, atender a ciertos intereses -concretamente, de tipo ecológico o ambiental- que no están contemplados expresamente en el Convenio Europeo -un instrumento circunscrito casi exclusivamente a la protección de derechos civiles y políticos-, es sin embargo imprescindible para garantizar la vigencia de su propio articulado.

El CEDH fue adoptado en el marco del Consejo de Europa en Roma, el 4 de noviembre de 1950. Al igual que otras declaraciones de derechos fundamentales coetáneas, aprobadas a consecuencia de la Segunda Guerra Mundial -como la Declaración Universal de los Derechos Humanos (I948)-, su finalidad esencial fue la de consagrar a nivel internacional, y ofrecer una protección firme, a los derechos de tipo individual o de primera generación. Su núcleo de interés gravitaba aún lejos, por lo tanto, de intereses de tipo supraindividual, y más aún de una cuestión que, como la degradación de los ecosistemas, aún no había adquirido una presencia determinante en las sociedades industriales, y menos aún como problema jurídico. De hecho, los aspectos ecológicos no fueron tomados en consideración formalmente por la comunidad internacional hasta la Conferencia de las Naciones Unidas sobre el Medio Humano, celebrada en Estocolmo en junio de $1972^{3}$. La diversidad de Estados que integran el Consejo de Europa, y la complejidad de su funcionamiento, han impedido, hasta la fecha, que el catálogo de derechos del CEDH se amplíe hasta los llamados de tercera generación, entre los que se enmarca el derecho a un

«era tecnológica», y de ciertas corrientes sociales como la ecología, el feminismo o los nacionalismos de diverso tipo. Las tres generaciones de derechos plasman, de forma sintética, unos determinados «valores generacionales»: libertad, igualdad y solidaridad (referida incluso a las generaciones futuras), respectivamente. Más que el número de generaciones, que es un aspecto discutido en la doctrina -por ejemplo, una propuesta de sistematización basada en cuatro generaciones la podemos encontrar en SÁNCHEZ FÉRRIZ, R., Estudio sobre las libertades, Valencia: Tirant lo Blanch, I989, p. 93 y ss.-, lo relevante es atender a las condiciones sociopolíticas que impulsaron la reivindicación y, en su caso, reconocimiento de cada derecho, y los valores subyacentes a los que éstos responden.

2 PÉREZ LuÑo, A.E., «Estado constitucional y derechos de la tercera generación», Anuario de Filosofia del Derecho, I3-14, I996-I997, p. 564.

${ }^{3}$ El Primer principio de la Declaración de Estocolmo afirma: «El hombre tiene el derecho fundamental a la libertad, a la igualdad y al disfrute de condiciones de vida adecuadas en un medio de calidad tal que le permita llevar una vida digna y gozar de bienestar y tiene la solemne obligación de proteger y mejorar el medio para las generaciones presentes y futuras». Se trata del primer reconocimiento internacional del derecho humano a un medio ambiente adecuado. 
medio ambiente adecuado ${ }^{4}$. Sin embargo, el Consejo de Europa sí ha mostrado una cierta sensibilidad hacia la cuestión ambiental a través de su labor legislativa, dirigida a la armonización de los ordenamientos de los Estados miembros, aprobando varias Resoluciones y Convenios de contenido específicamente medioambiental5.

Al margen de esta labor legislativa, y circunscribiéndonos al ámbito del CEDH, atenderemos a la significativa labor desarrollada por los dos órganos judiciales del Consejo de Europa, el TEDH y la Comisión, a través de su jurisprudencia con vinculaciones hacia la protección del medio ambiente. Pese a la ausencia en el articulado del CEDH, como decíamos, de derechos subjetivos específicamente ambientales, estos órganos vienen llevando a cabo una verdadera labor pretoriana, dando entrada tangencialmente a intereses ambientales a través de la técnica del efecto reflejo (protection par riochet, según la doctrina francesa). Ello, a partir de la consideración de que ciertos derechos sí reconocidos por el Convenio implican, en su efectiva realización, una protección del medio ambiente. Si bien el tenor literal del CEDH impide que una acción lesiva contra un ecosistema pueda ser objeto en sí misma de recurso, los órganos tuitivos del Convenio se han declarado competentes para conocer de dicho ataque cuando éste impida o limite gravemente el disfrute efectivo de un derecho reconocido expresamente en el articulado. El corpus jurídico resultante constituye la denominada «jurisprudencia ambiental» del TEDH y la Comisión.

A través del valor de la ratio decidendi de sus sentencias, que va más allá del mero efecto de cosa juzgada inter partes, el TEDH ha puesto de manifiesto la dimensión ambiental de derechos individuales, como el respeto a la vida privada y familiar e inviolabilidad del domicilio (art. $8 \mathrm{CEDH}$ ), llevando a cabo un proceso de ampliación del ámbito de cobertura de estos derechos, y permitiendo la adaptación del Convenio a la evolución social. Esta labor hermenéutica implica un doble reconocimiento. Por un lado, la necesidad de dar una respuesta efectiva al fenómeno de la «contaminación de las libertades» (libertie's pollution), producida a consecuencia del desarrollo de la era tecnológica ${ }^{6}$. Por otro, la virtualidad que presenta el derecho al medio ambiente como presupuesto inexcusable para el ejercicio de otros derechos o como límite a los mismos, en

${ }^{4}$ En I973, el Gobierno alemán propuso la adopción de un Protocolo adicional al CEDH que contenía dos disposiciones: la proclamación del derecho a la salud, que conllevaba el derecho de no ser expuesto a cambios adversos en las condiciones naturales de vida que pudieran amenazar la salud o el bienestar personales; y la instauración de un procedimiento de reparación frente a los daños al medio ambiente provocados por los particulares. Esta iniciativa no encontró el cauce jurídico oportuno por falta de voluntad de los Estados, y desde entonces no se ha producido ninguna otra propuesta en este sentido. Sin embargo, el derecho al medio ambiente sí aparece consagrado en dos de los otros sistemas regionales de protección de los Derechos Humanos. La Convención Americana sobre derechos humanos establece en el artículo i de su Protocolo adicional que «I. Toda persona tiene derecho a vivir en un medio ambiente sano y a contar con servicios públicos básicos. 2. Los Estados Partes promoverán la protección, preservación y mejoramiento del medio ambiente». Por su parte, el artículo 24 de la Carta Africana sobre Derechos del Hombre y de los Pueblos («Carta de Banjul») afirma que «Todos los pueblos tienen el derecho a un satisfactorio medio ambiente favorable para su desarrollo». En el incipiente sistema árabe, la Carta de Derechos Humanos y de los Pueblos, a pesar de su reciente aprobación (i5 de septiembre de I994), no contiene ninguna previsión en materia medioambiental. Sin embargo, en el ámbito comunitario europeo, la política medioambiental sí aparece como un objetivo expreso entre las preocupaciones de la Unión, a partir la reforma de los Tratados Constitutivos por el Acta Única Europea.

${ }^{5}$ Cabe citar el Convenio de Berna sobre conservación de la vida salvaje y del medio natural en Europa (I979), el Convenio de Lugano sobre responsabilidad civil por daños resultantes de actividades peligrosas para el medio ambiente (I993), la Resolución (77) 28 sobre la contribución del Derecho penal en la protección del medio ambiente, o la Resolución Núm. I relativa a la protección del medio ambiente por el Derecho penal, de la $\mathrm{I}^{\mathrm{a}}{ }^{\mathrm{a}}$ Conferencia de ministros europeos de Justicia (que tuvo lugar en Estambul en junio de I990), entre otros.

\footnotetext{
${ }^{6}$ PereZ LUÑO, A.E., op. cit., p. 564 .
} 
un contexto histórico en el que el desbordamiento de la capacidad de carga de los ecosistemas, ha hecho patente la necesidad de adoptar planteamientos que se dirijan a reconsiderar algunas de las dinámicas que han dominado el desarrollo social desde la revolución industrial.

La labor desarrollada por el TEDH y la Comisión en esta materia ha sido de tipo expansivo. En una primera aproximación, podría deducirse que las diferencias técnicas y conceptuales entre los derechos, que refleja su división generacional, supone un límite infranqueable para la tutela de valores propios de las últimas generaciones con base en el CEDH. Sobre todo, si tenemos en cuenta el carácter esencialmente negativo de las libertades de la primera generación, frente al carácter positivo de los derechos sociales y culturales y los de solidaridad, que implican una actividad pública que va más allá de la clásica doctrina liberal del laissez faire. No obstante, la interpretación de los órganos judiciales europeos se ha dirigido a afirmar que, pese a su origen histórico, las obligaciones que derivan del Convenio para los Estados partes no son exclusivamente de carácter negativo, sino que los poderes públicos tienen, en determinadas circunstancias, el deber de actuar aportando los medios necesarios para garantizar los derechos enunciados en el texto.

El ejemplo más evidente de esta doctrina es, quizá, la jurisprudencia desarrollada en relación al art. 8 del Convenio (derecho a la vida privada y familiar y a la inviolabilidad del domicilio), a raíz de su aplicación a diversas situaciones de contaminación ambiental en la que se vieron afectados, de forma concreta, determinados sujetos individuales. El ámbito originario del art. $8 \mathrm{CEDH}$, la protección de un ámbito concreto de intimidad individual frente a posibles injerencias arbitrarias de los poderes públicos, ha quedado notablemente ensanchado. Ya en el asunto Airey contra Irlanda (STEDH de 9 de octubre de 1979), el Tribunal tuvo ocasión de afirmar que, realmente, el papel del Estado «no queda reducido a ese deber de abstención de injerencias: junto con ese fundamental aspecto negativo puede haber deberes positivos inherentes a una protección efectiva de la vida privada y familiar» (parágrafo 3I).

Como veremos, esta hipótesis expansiva es uno de los puntos de partida de la llamada jurisprudencia ambiental del TEDH, y dentro de ella, el núcleo en torno al que gravita el razonamiento del asunto López Ostra contra España (STEDH de 9 de diciembre de I994), leading case en la protección indirecta del medio ambiente a través del art. 8 CEDH. Anticipando lo que será objeto de análisis inmediatamente, en dicho asunto el Tribunal advirtió que, cuando el ámbito de indemnidad de los individuos, protegido por el Convenio, se ve invadido a consecuencia de un atentado contra el medio ambiente, que tiene su causa en una actividad administrativa o en el desfallecimiento de los poderes públicos en hacer cumplir la normativa dictada en protección de aquél, pueden encontrarse implicados derechos fundamentales cuyo reconocimiento protege aquel reducto de indemnidad. Precisamente, en el asunto López Ostra el Tribunal no sustenta la infracción del art. 8 en la inmisión medioambiental (que fue originada por la actividad de una persona jurídica privada, cuyo control escapa, por tanto, al ámbito competencial del TEDH), sino en la pasividad de la Administración competente para adoptar las medidas conducentes a hacer cesar aquélla ${ }^{7}$.

En definitiva, el TEDH supera la división generacional de los derechos fundamentales con base en la continuidad y las relaciones de retroalimentación existentes entre ellos, y sobre la constatación de que éstos pueden ser vulnerados por el Estado tanto activa como omisivamente. Y todo ello, a partir de la defensa implícita por el Tribunal y la Comisión de la necesidad de interpretar con flexibilidad las normas legales a la luz de las

\footnotetext{
${ }^{7}$ STEDH de 9 de diciembre de I994, parágrafos 8, 27 y 28.
} 
condiciones de existencia de cada momento histórico, como vía imprescindible para garantizar una protección real y efectiva del individuo.

Estas conclusiones son, si cabe, más vigentes aún en el ámbito del derecho al medio ambiente, dadas las peculiaridades del mismo, como prius para el disfrute de cualquier otro derecho.

\section{El medio ambiente como bien jurídico.}

A raíz del prolongado proceso de evolución teórica que constituye la mencionada «jurisprudencia ambiental», un sector de la doctrina ha sostenido que el TEDH ha venido a reconocer el derecho a un medio ambiente adecuado como un auténtico derecho humano, implícito en el Convenio Europeo. De hecho, algunos pronunciamientos del Tribunal parecen, en una primera aproximación, avalar expresamente esa hipótesis. Tal es el caso de la doctrina expuesta por el juez Greve en el asunto Hatton y otros contra el Reino Unido (STEDH de 2 de octubre de 200I), donde aquél sostiene que, de la propia jurisprudencia del TEDH, se desprende el reconocimiento de los derechos medioambientales como una nueva generación de derechos humanos. En este sentido, algunos autores han visto en la resolución del asunto López Ostra contra España la consagración por el TEDH de un auténtico derecho subjetivo a un medio ambiente sano ${ }^{8}$. Una afirmación discutida, en cambio, por aquellos para quienes el TEDH no ha llegado aún tan lejos -y cabría decir que, en realidad, no puede llegar tan lejos- en sus pronunciamientos. En cualquier caso, no deja de ser paradójico que el debate sobre la existencia de un derecho fundamental al medio ambiente se haya suscitado por una vía tan colateral como es el derecho a la vida personal y familiar. Ello sólo es posible en virtud de la peculiar naturaleza del medio ambiente como interés jurídico protegible. El análisis de la jurisprudencia ambiental del TEDH exige realizar algunas precisiones sobre dicho concepto.

Una simple mirada a la literatura jurídica ambiental evidencia que la consideración del bien jurídico medio ambiente dista mucho de ser pacífica. En la doctrina constitucionalista española es ya habitual el debate sobre el reconocimiento o no, ex art. 45 de la Constitución de 1978, de un verdadero derecho subjetivo a un medio ambiente adecuado. Lo mismo puede decirse sobre la defensa del manejo de un concepto jurídico amplio o restrictivo de ambiente, o sobre la orientación general del ordenamiento jurídicoambiental.

La dificultad de aprehensión del concepto de ambiente desde un punto de vista jurídico deriva de su propia generalidad e indefinición. Como señala Lozano Cutanda, si bien esto es algo que ocurre con todos los derechos fundamentales, en este caso la indefinición es absoluta, dado el carácter transversal de este bien jurídico ${ }^{9}$. Concretamente, la falta de claridad en el manejo del concepto «medio ambiente» deriva del hecho de que éste es utilizado como un concepto maleable, haciendo referencia, en cada caso, a objetos distintos. De forma que, al hablar de «protección jurídica del medio ambiente» o de «medio ambiente adecuado», podemos estar refiriéndonos en realidad a la protección de intereses

\footnotetext{
${ }^{8}$ Así lo advierte, por ejemplo, BOUAZZA ARIÑO, O., «Respeto a la vida privada y protección del medio ambiente en la jurisprudencia del Tribunal Europeo de Derechos Humanos», Revista de Administración pública, I6o, enero-abril 2003, p. I74 (nota a pie $\mathrm{n}^{\circ} 8$ ).

${ }^{9}$ LOZANO CUTANDA, B., «La ecologización de los derechos fundamentales: la doctrina López Ostra c. España, Guerra y otros c. Italia y Hatton y otros c. Reino Unido del TEDH y su recepción por nuestro TC», REDE, I, 2002, p. I77.
} 
de muy distinta amplitud. La transversalidad del concepto, que hace del ambiente un prius respecto a la protección de cualquier otro bien jurídico, determina que existan múltiples intereses reconducibles a la idea de medio ambiente adecuado. Y, a la inversa, que existan diversos bienes jurídicos que puedan ser preservados a través de la protección del ambiente. Podríamos decir que el concepto de medio ambiente, desde un punto de vista jurídico, es en realidad un concepto en blanco, cuyo contenido debe ser cubierto haciendo referencia a terceros bienes o intereses. La fórmula «medio ambiente adecuado» refleja bien la estructura del bien jurídico, en la medida en que el término «adecuado» remite a ideas externas. El enunciado sugiere rápidamente la pregunta de para qué debe ser adecuado el ambiente, ante la que caben respuestas muy distintas, que serán las que determinen, en definitiva, la mayor o menor amplitud del concepto: adecuado para garantizar la vida o la salud humana, para la vida del resto de integrantes de los ecosistemas, para garantizar la proyección de esa vida hacia el futuro... o incluso adecuado para el desarrollo de la vida privada y familiar. Porque aunque, siendo precisos, en la línea jurisprudencial culminada por el caso López Ostra el TEDH otorga protección al ambiente a través de la protección de la vida privada y familiar, no podemos obviar que, en realidad, con ello se está afirmando que ese derecho a la vida privada y familiar forma parte del concepto jurídico de medio ambiente. Como veremos, este hecho plantea el problema técnico de que el Tribunal esté definiendo, de facto, el contenido de un derecho no recogido en el catálogo del Convenio, y con ello, quizá, extralimitándose en sus funciones.

En cualquier caso, la interpretación dada por el TEDH y la Comisión al art. 8 CEDH es un claro ejemplo de esa retroalimentación entre derechos. Pero, evidentemente, el contenido del concepto de ambiente no puede estar limitado a intereses individuales como el respeto a la vida personal y familiar, o incluso la salud y la vida del individuo. Como decíamos, el concepto de ambiente es muy elástico. Con el fin de clarificar este aspecto, y de forma muy simplificada, el bien jurídico medio ambiente podría representarse idealmente en diversos círculos concéntricos. Los círculos centrales representarían aquellos intereses de tipo humano y más estrictamente individuales, que se identifican con los derechos liberales más clásicos: vida, salud e integridad física... y también el derecho a la vida personal y familiar y la inviolabilidad de domicilio; en los siguientes círculos del gráfico hipotético se situarían aquellos intereses humanos de ámbito más amplio que el estrictamente individual: los derechos de las generaciones futuras o los derechos de los consumidores -que presentan estrechos lazos con la protección de diversos intereses ambientales-, por poner algunos ejemplos; en los círculos exteriores de nuestro dibujo se encontrarían aquello intereses de tipo no específicamente antrópico, como los -hipotéticosderechos de los animales no humanos. Como vemos, la noción de medio ambiente varía notablemente según a qué derechos apliquemos el adjetivo de «adecuado». Esta representación ideal refleja, además, el distinto nivel de protección de los intereses en los ordenamientos jurídicos actuales de corte liberal. Los bienes jurídicos situados en los círculos centrales (de tipo estrictamente individual) gozan de una protección más intensa, que se difumina conforme nos desplazamos hacia el exterior: la respuesta del ordenamiento es más efectiva cuando un atentado contra el medio afecta directamente a los derechos individuales de alguna persona concreta -por ejemplo, a su vida o su salud-. Hasta llegar a los círculos más alejados, donde los intereses no reconducibles al ser humano chocan con la propia estructura del ordenamiento basada en la categoría de derecho subjetivo, quedando privados de protección. Si bien ello no es obstáculo para considerar, en un plano axiológico, la conveniencia de extender el reconocimiento de derechos más allá de la barrera de lo humano ${ }^{\mathrm{IO}}$.

Io En este sentido, en nuestro entorno sociojurídico puede consultarse MOSTERÍN, J. Y Riechmann, J., Animales y ciudadanos. Indagación sobre el lugar de los animales en la moral y el derecho de la sociedades industrializadas, Madrid: Talasa, I995. En el ámbito anglosajón, donde este debate se encuentra mucho más desarrollado, puede acudirse a la bibliografía de Gary L. Francione, 
El carácter transversal del concepto jurídico de ambiente queda demostrado si pensamos que, no obstante, la protección de los intereses situados en los círculos centrales a menudo redundará en la protección de los intereses de todo el sistema en su conjunto, incluso de aquellos que no gozan de una protección directa por el ordenamiento.

Este esquema puede ayudar a comprender mejor la sintética frase del TEDH en relación al asunto López Ostra, al afirmar que «graves ataques sobre el medio ambiente pueden afectar al bienestar de una persona y privarla del derecho a la tranquilidad del domicilio, de manera que su vida privada y familiar pueden verse perjudiciadas sin que se ponga en grave peligro su salud» (parágrafo 5I).

\section{Evolución de la jurisprudencia ambiental del TEDH y la Comisión.}

La sentencia dictada en relación al asunto López Ostra contra España provocó un inmediato interés en la doctrina española, ya que a la relevancia de su contenido se une el hecho de que el Estado condenado fuese precisamente el español. No cabe duda de que dicha sentencia es una pieza de enorme importancia en la jurisprudencia del TEDH y de la Comisión, pero quizá sea precipitado calificarla de revolucionaria, como se puede leer en algunos estudios cercanos en el tiempo a la resolución. La razón es que, en realidad, el caso López Ostra no supone ninguna ruptura o «salto en el vacío» en la jurisprudencia del Tribunal y la Comisión, sino que es un paso más, un paso importante sin duda, en una línea evolutiva cuyos antecedentes remotos hay que buscar en los últimos años setenta ${ }^{\mathrm{II}}$. Podría decirse que la respuesta dada al asunto López Ostra era un paso lógico dentro de un camino bien definido.

A continuación, realizaremos un rápido recorrido por los pronunciamientos que conforman la llamada jurisprudencia ambiental del TEDH y la Comisión, de forma cronológica, queriendo hacer hincapié precisamente en esa idea de progresión evolutiva. Por ello deben ser consideradas algunas resoluciones que, si bien no presenta un contenido específicamente ambiental, son pasos fundamentales en esa progresión. Por otro lado, en este recorrido no sólo es protagonista el Tribunal Europeo de Derechos Humanos, sino también la Comisión, de ahí que en el enunciado nos refiramos a la jurisprudencia de ambos. Pese a que suele ser relegada habitualmente a un segundo plano ${ }^{\mathrm{I} 2}$, la Comisión Europea de los Derechos Humanos tiene un papel clave en la tutela del Convenio. Su función de filtro previo, examinando la admisibilidad de las demandas, implica un poder decisorio definitivo sobre aquello de lo que conocerá el Tribunal, por lo que su incidencia en el sistema de protección es determinante. Además, los pronunciamientos contenidos en sus dictámenes sirven a menudo de base para la elaboración de las resoluciones del

especialmente Francione, G.L., Animals, property, and the law, Philadelphia: Temple University Press, I995.

${ }^{\text {II }}$ Así lo han sostenido GARCíA SAN JOSÉ, D., «Derecho al medio ambiente y respeto a la vida privada y familiar (Comentario a al STEDH de 9 de diciembre de I994)», La Ley, 4, I995, p. I203, y CARRILlO DONAIRE, J.A. y GALAN VIOQUE, R., «¿Hacia un derecho fundamental a un medio ambiente adecuado? (Comentario en torno al asunto López Ostra c. España, resuelto por la sentencia del Tribunal Europeo de Derechos Humanos de 9 de diciembre de I994)», REDA, 86, abril-junio I995, p. 277.

${ }^{12}$ En este sentido, vid. JIMEnA QuesadA, L. y TOMÁS MAllÉN, B.S., op. cit., p. 2I5I y 2I52. Estos autores advierten que, no en vano, «las decisiones e informes de la Comisión (...) también son definitivos cuando se trata de decisiones de inadmisibilidad o de informes que en la última fase no son sometidos al TEDH dentro del plazo de 3 meses previsto en el artículo 32 CEDH». 
Tribunal. Como veremos inmediatamente, en el tema que nos ocupa el papel de la Comisión ha sido relevante.

El primer paso en la protección jurisprudencial (indirecta) del ambiente en aplicación del CEDH puede situarse en el asunto X. e Y. contra Alemania, pese a que éste no llegara a suscitar un pronunciamiento del Tribunal. La demanda fue presentada por una asociación ecologista, que acudió al TEDH para denunciar las prácticas militares que se realizaban en unas zonas pantanosas cercanas a la localidad donde vivían los miembros de la asociación. Los actores fundaron su demanda en el menoscabo de su derecho a la vida (art. $2 \mathrm{CEDH}$ ) y a la libertad (art. $5 \mathrm{CEDH}$ ), y en la violación de la prohibición de la tortura (art. 3 CEDH). La Comisión inadmitió la demanda, argumentando que el Convenio no reconoce expresamente el derecho a la conservación de la naturaleza. El hecho que hace de este caso el primer antecedente de la línea jurisprudencial que nos ocupa es, precisamente, el contenido de la decisión de la Comisión.

En su función decisoria sobre la admisibilidad de la demanda, las razones por las que la Comisión puede determinar la incompatibilidad de una determinada pretensión con las disposiciones del Convenio son de dos tipos: ratio materiae, si los actores han invocado un derecho que no figura entre los reconocidos en el sistema del Convenio, y ratio personae, si no concurren las condiciones necesarias en el demandante conforme al art. 25 CEDH. La incompatibilidad ratio materiae había sido hasta ese momento la causa de inadmisibilidad de las demandas en las que se invocaba la violación del Convenio a consecuencia de una agresión medioambiental. Pero en esta decisión, la Comisión dio un giro en el tratamiento de este tipo de demandas. No se limitó a declarar esa incompatibilidad, sino que, por primera vez, analizó en qué medida un ataque medioambiental puede incidir en el efectivo goce de algunos de los derechos garantizados en el Convenio, y en qué circunstancias podría un particular reclamar un eventual derecho a condiciones medioambientales adecuadas.

El siguiente hito significativo lo constituye el ya mencionado asunto Airey contra Irlanda (SETDH de 9 de octubre de I979). Aunque éste no versara sobre temas ambientales, supone un importante hito en la jurisprudencia del TEDH, y un paso que posibilitó, entre otras, la condena al Estado español, dos décadas después, en el asunto López Ostra. Como hemos visto más arriba, el TEDH afirmó en esta sentencia que el papel del Estado en cuanto al respeto del CEDH no queda reducido al deber de abstención de injerencias, sino que «junto con ese fundamental aspecto negativo puede haber deberes positivos inherentes a una protección efectiva de la vida privada y familiar» (parágrafo 3I). En definitiva, esta argumentación eleva de forma considerable el nivel de exigencia a los Estados en orden a la protección de los derechos fundamentales, y amplía las posibilidades de condena. Esta afirmación tiene, quizá, más importancia en el ámbito de la protección ambiental, ya que muchas injerencias ilegítimas a derechos reconocidos en el Convenio a consecuencia de agresiones ambientales provendrán de sujetos privados (normalmente personas jurídicas, como empresas). Dado que el Tribunal no es competente para conocer de agresiones entre particulares, estos casos nunca podrían llegar al TEDH si no fuera posible afirmar la responsabilidad de los poderes públicos competentes por inactividad $u$ omisión en la protección efectiva de los derechos lesionados.

En el asunto Arrondelle contra el Reino Unido (Decisión de la Comisión de I5 de julio de I980), nos encontramos de nuevo ante un pronunciamiento de la Comisión. En este supuesto, el asunto no trascendió al Tribunal por alcanzar previamente las partes un acuerdo amistoso. Pese a ello, se trata de una decisión clave en la incorporación al Convenio de condiciones ambientales adecuadas vía el art. 8 CEDH. Los hechos consistían en la acentuada situación de estrés sufrida por la demandante en su propio domicilio, a consecuencia de su ubicación entre una carretera con elevado tráfico y el final de la pista de aterrizaje del aeropuerto internacional de Gatwick. La Comisión declaró admisible la 
demanda, basada en las graves molestias acústicas padecidas por la actora, que suponían una injerencia ilegítima en su derecho a la vida privada y familiar y a la inviolabilidad de domicilio.

Este asunto no sólo supone un hito en hito en la interpretación ambiental del art. $8 \mathrm{CEDH}$, sino que además inaugura la importante línea jurisprudencial del TEDH sobre el ruido, incardinada dentro de la protección indirecta del ambiente.

En la Sentencia del TEDH de 24 de septiembre de 1982, referente al asunto Sporrong y Lönnroth contra Suecia, tuvieron eco cierto los intereses del ambiente y la estética urbana, pese a que su núcleo fundamental versara sobre el derecho de propiedad. Los herederos del señor Sporrong y la señora Lönnroth presentaron la demanda ante la Comisión por el otorgamiento de permisos de expropiación recaídos sobre sus propiedades situadas en la ciudad de Estocolmo, con motivo de las mejoras que se pretendían realizar en el centro de la capital sueca. Dichos permisos fueron acompañados de las correspondientes prohibiciones de construir, que se prolongaron durante veinticinco y doce años respectivamente. Transcurrido ese tiempo, los permisos de expropiación fueron anulados debido a un cambio en la política urbanísitica en los años setenta, dirigida a limitar el tráfico del centro de la ciudad para proteger el entorno urbano y conservar la fisonomía característica de los edificios existentes. El TEDH decidió que se había producido una violación del derecho de propiedad de los demandantes (Art. I del Protocolo adicional $\mathrm{n}^{\circ} \mathrm{I}$ ), dado que se les había impedido el disfrute efectivo del mismo.

El valor de esta sentencia radica en que pone ya de manifiesto el manejo por parte del TEDH de un concepto amplio de ambiente, evitando el extendido prejuicio de oponer lo natural y lo urbano. Realmente, como afirma Bassols Coma, no existe una frontera tajante entre urbanismo y medio ambiente, siendo un error considerar que el medio ambiente se limita a la flora y la fauna y el derecho urbanístico al espacio urbano ${ }^{\mathrm{I}}$.

El siguiente caso en la línea jurisprudencial referente al impacto de los grandes aeropuertos lo encontramos en la sentencia de 3 de octubre de I983, en el caso Zimmermann y Steiner contra la Confederación Helvética. Los demandantes acudieron a la jurisdicción interna alegando el daño causado por el ruido y la polución del aire a consecuencia del aeropuerto Zurcí-Kloten. El Tribunal Federal se retrasó en la emisión del fallo en un caso sin excesiva complicación, lo que provocó que los demandantes acudieran a Estrasburgo por la vía del art. 6.I, invocando la exigencia de dictar justicia en un plazo razonable. Sin embargo, y dada la fundamentación de la demanda, el fondo del asunto no tiene mayor interés para el estudio que nos ocupa.

Ese mismo año se planteó ante el TEDH un caso del máximo interés, tanto desde el punto de vista de la protección indirecta del ambiente como de la relación entre las distintas generaciones de derechos humanos. Se trata del caso G. y E. contra Noruega (SETDH de 3 de octubre de I983), en el que confluyen dos supuestas violaciones de derechos humanos de los llamados «colectivos» o de «última generación»: medio ambiente y derechos de las minorías.

El Gobierno noruego había decidido construir una central hidroeléctrica en el emplazamiento conocido como Alta Valley, lo cual conllevaba la creación de un lago artificial que inundaría una parte de la tierra utilizada tradicionalmente por los lapones noruegos. Los demandantes denunciaron ante la Comisión que la construcción proyectada significaba atentar contra la base misma de su existencia, lo que les forzaría a incorporarse

${ }^{13}$ BASSOLS COMA, M., «Propiedad privada y cuestiones de medio ambiente», en BARNÉS, J. (coord.), Propiedad, expropiación y responsabilidad. La garantía indemnizatoria en el derecho europeo $Y$ comparado, Madrid: Tecnos y Junta de Andalucía, ı996, p. 728. 
a la sociedad noruega, una sociedad totalmente diferente a la propia. Tras recordar que el CEDH no protege derechos de las minorías en cuanto a tales, la Comisión señaló que, sin embargo, el estilo de vida de una minoría, en principio, también puede caer bajo la protección del artículo $8 \mathrm{CEDH}$, y que, en virtud de ello, las consecuencias de la construcción del lago artificial constituían una injerencia en la vida privada de los demandantes. La admisión de la demanda por una agresión ambiental con base en el artículo 8 CEDH ya contaba con el precedente del caso Arrondelle contra el Reino Unido, pero en aquel supuesto el Tribunal no tuvo ocasión de pronunciarse. Así pues, la del asunto que nos ocupa supone el primer pronunciamiento del TEDH sobre la aplicación del art. 8 del Convenio por una supuesta agresión ambiental.

El Tribunal desestimó las pretensiones de los demandantes por aplicación del párrafo segundo del propio artículo 8:

«No podrá haber injerencia dela autoridad pública en el ejercicio de este derecho, sino en tanto en cuanto esta injerencia esté prevista por la ley y constituya una medida que, en una sociedad democrática, sea necesaria para la seguridad nacional, la seguridad pública, el bienestar económico del país, la defensa del orden y la prevención del delito, la protección de la salud o de la moral, o la protección de los derechos y las libertades de los demás.»

El TEDH entendió que, pese a que la injerencia en el derecho de los actores existió, el fin perseguido por la construcción de la presa era legítimo, en tanto que estaba justificado por el interés del bienestar económico del país.

Los dos siguientes casos que citaremos se refieren, de nuevo, a las molestias causadas por los grandes aeropuertos. Y en ambos, los demandantes se veían afectados por el aeropuerto londinense de Heathrow.

El primero de ellos es el asunto Baggs contra el Reino Unido (Decisión de la Comisión de i6 de octubre de I985). El asunto no trascendió al Tribunal por haberse logrado un acuerdo amistoso entre las partes. Pero la Comisión sí tuvo ocasión de pronunciarse, estableciendo, como ya había hecho anteriormente, que el ruido ambiental producido en los alrededores del aeropuerto de Heathrow era susceptible de violar la intimidad de la vida familiar, declarando en consecuencia admisible la demanda. El segundo, ubicado ya en la década de los noventa, es un supuesto de gran trascendencia dentro de la jurisprudencia del TEDH referente al ruido, y más generalmente, de la jurisprudencia ambiental del Tribunal Europeo. Se trata del asunto Powell $y$ Rayner contra el Reino Unido (STEDH de 2I de febrero de I990), que es paradigmática dentro de la protección indirecta del ambiente en el ámbito del CEDH, al mismo nivel que el asunto López Ostra.

Si lo visto hasta el momento constituían sus antecedentes o cimientos, podemos afirmar que el caso Powell $y$ Rayner inaugura de forma explícita la línea jurisprudencial, basada en el artículo $8 \mathrm{CEDH}$, en la que el Tribunal realiza la labor hermenéutica consistente en afirmar que determinados daños al medio ambiente pueden lesionar, y de hecho lesionan, derechos fundamentales como el respeto a la intimidad y el goce pacífico del domicilio. El Tribunal se pronunció en los siguientes términos:

«El ruido de los aviones del aeropuerto de Heathrow ha disminuido la calidad de la vida privada y el disfrute del hogar de los demandantes, aunque en grados muy distintos. Por consiguiente, el artículo 8 ha de tenerse en cuenta en relación a los señores Powell y Rayner» (parágrafo 40). 
Las partes fundaron sus pretensiones en cuatro argumentos distintos. Dos de tipo procesal: derecho de acudir ante un tribunal civil (art. 6.I CEDH) y derecho a un recurso jurisdiccional efectivo (art. I3); y dos de tipo material: derecho al respeto de la vida privada y del domicilio (art. 8) y derecho al respeto y disfrute de sus bienes (art. $\mathrm{I}^{\mathrm{o}}$ del Protocolo I al $\mathrm{CEDH})$. De este conjunto de pretensiones destaca la doble vía de actuación de los demandantes, argumentando, paralelamente al derecho a la intimidad, el derecho a la propiedad, como si el ruido estuviese incidiendo sobre ambos valores jurídicos. Si en el asunto Sporrong y Lönnroth contra Suecia aparecía ya apuntada la potencialidad del uso del derecho de propiedad también como vía indirecta de preservación medioambiental (en aquel caso referido al entorno urbano), en el asunto Powell $y$ Rayner esa posibilidad aparece manifestada de forma inequívoca en la demanda. El carácter transversal y referencial del bien jurídico ambiente conduce nuevamente a conclusiones paradójicas: si bien el derecho de propiedad suele esgrimirse como un interés a limitar desde el punto de vista de la protección del medio ambiente, vemos que no pueden desecharse supuestos en los que la situación sea exactamente la opuesta.

No obstante, la Comisión admitió únicamente la queja referente a la violación del artículo I3 en relación con el artículo 8. Es decir, acotó el conocimiento del caso por parte del TEDH a una hipotética violación del derecho de los demandantes a un recurso jurisdiccional efectivo para la tutela de su derecho a la vida privada y familiar e inviolabilidad del domicilio. De esta decisión podemos extraer al menos dos conclusiones importantes. Por un lado, la Comisión rechaza la aplicabilidad de la garantía de la propiedad como defensa frente a la emisión de ruidos del aeropuerto. Por otro, rechaza también la aplicación autónoma de la garantía de la intimidad (art. 8) ${ }^{\mathrm{I}}$. La Comisión declara, por tanto, que la única reclamación que puede cursarse ante el TEDH es la referente a la tutela judicial efectiva para poder hacer valer el derecho a la intimidad.

En esos términos llegó el caso a manos del Tribunal, quien, al igual que sucedió en el asunto G. Y E. contra Noruega, basó su decisión en el párrafo segundo del artículo 8, que como vimos recoge ciertos límites legítimos al derecho reconocido en el párrafo primero. Nuevamente, el TEDH entiende que, aunque la injerencia en el derecho a la intimidad domiciliaria de los demandantes existió, ésta estaba justificada atendiendo al interés del bienestar económico del país. No obstante, y pese al fallo desestimatorio de la demanda, el valor de esta sentencia radica en que el Tribunal no ofrece en ella ninguna duda de que el problema del ruido encaja en el artículo 8, admitiéndolo como un factor contaminante capaz de incidir en la calidad de la vida privada y el disfrute del domicilio.

Por último, hay que destacar que el TEDH reitera en esta sentencia su doctrina referente a las obligaciones positivas de los Estados para la garantía de los derechos fundamentales, acuñada en el asunto Airey contra Irlanda. El Tribunal recuerda que, pese a que los derechos reconocidos en el artículo 8 no tienen carácter absoluto, no obstante, obligan a los Estados a adoptar las medidas, incluso de carácter positivo, que sean necesarias para garantizar su efectividad.

Los casos analizados hasta ahora presentan la nota común de que la posibilidad de utilización del Convenio con fines de conservación medioambiental pasaba por la estimación por parte del Tribunal de las pretensiones de los demandantes, pese a que aquél se inclinase a entender justificada la limitación de los derechos de los actores por razones de economía nacional. Sin embargo, en el asunto Pine Valley Developments LTD. y otros contra Irlanda (STEDH de 29 de noviembre de I99I) ocurre lo contrario. En este supuesto, si bien el Tribunal entendió que, nuevamente, la injerencia en los derechos de los

\footnotetext{
${ }^{\text {I4 }}$ MARTIN-ReTORTILlO BAQUeR, L., «El ruido de los grandes aeropuertos en la jurisprudencia del Tribunal Europeo de Derechos Humanos», en VV.AA., Derecho del medio ambiente, Madrid: Centro de Estudios Jurídicos de la Administración de Justicia, I995, p. I26.
} 
demandantes estaba justificada, no lo hizo basándose en criterios de preferencia económica, sino precisamente en razones de preservación del medio. El Tribunal otorgó una tutela de tipo medioambiental mediante la desestimación de la demanda.

El asunto versaba sobre una compra de terrenos por la empresa Pine Valley Developments para realizar actividades de compostaje industrial. La compra se efectuó confiando en una licencia provisional que, según el ordenamiento irlandés, precisa de una licencia definitiva una vez iniciadas las obras y transcurridos tres años desde la concesión de la inicial. La licencia provisional había sido otorgada por el Minister for Local Government, en apelación planteada por la empresa frente a la denegación de licencia por la autoridad urbanística. Sin embargo, la licencia definitiva fue finalmente denegada, ya que, de acuerdo con la normativa de ordenación urbana, no estaba permitido el desarrollo urbanístico en la zona donde se pretendían desarrollar las actividades industriales, al estar protegida por su especial valor natural. Por lo que la inicial y nula licencia otorgada, que condujo a los demandantes a comprar los terrenos, y la denegación posterior, produjeron una limitación del contenido del derecho de propiedad de los demandantes. Así lo constató el Tribunal, que, sin embargo, entendió que esa limitación estaba justificada por el superior interés ambiental concurrente.

El asunto Zander contra Suecia (STEDH de 25 de noviembre de I993) constituye el precedente inmediato de la sentencia López Ostra. El hecho de que el asunto gire en torno a consideraciones procesales no oscurece el hecho de que, según Jimena Quesada y Tomás Mallén, esta sentencia abra de manera decisiva la vía para el reconocimiento de un derecho subjetivo a la protección del medio ambiente ${ }^{15}$. Más adelante tendremos ocasión de analizar si, realmente, el TEDH ha reconocido la existencia de un derecho de tales características en el marco del Convenio.

El fondo del asunto versó sobre la aplicación del artículo 6 CEDH en relación a un procedimiento iniciado en el plano interno frente a una decisión administrativa, que autorizaba a una sociedad privada a acumular desechos en un terreno próximo al domicilio del señor y la señora Zander. Los desechos contenían un alto grado de cianuro, que convertía el agua de uso común del propio pozo de los demandantes en no potable. Los demandantes solicitaron la adopción de medidas de precaución ante la actividad de tratamiento de residuos, petición desestimada por el Gobierno sueco, al entender que no existía vinculación entre las actividades del vertedero y la contaminación de las aguas del pozo de los demandantes, ante lo cual éstos acudieron al Tribunal de Estrasburgo. El TEDH entendió por unanimidad que se había producido una violación del artículo 6.I del Convenio, considerando que los actores tenían derecho a solicitar las medidas de precaución, ya que la legislación ambiental sueca imponía determinadas obligaciones a quien decida realizar actividades que puedan afectar negativamente al medio ambiente. Pese a que el fondo del asunto es de tipo procesal, el asunto tiene la relevancia de que el Tribunal reconociera que entre los «derechos y obligaciones civiles» a que se refiere el art. 6 CEDH se encuentra la protección del medio ambiente.

Después de este prolongado recorrido llegamos, por fin, al asunto López Ostra contra España (STEDH de 9 de diciembre de I994), considerado el leading case en la aplicación del artículo 8 CEDH frente a agresiones ambientales, por ser la primera condena a un Estado con base en dicha fórmula interpretativa. Además, supuso un punto de inflexión en la jurisprudencia del Tribunal, ya que desde entonces éste se ha mostrado cada vez más decido a ampliar esta vía de recurso ${ }^{16}$. Sin embargo, como apuntábamos más

\footnotetext{
${ }^{15}$ Jimena QUESADA, L. y TOMÁS MALlÉN, B.S., op. cit., p. 2I53.

${ }^{16}$ Una condena más reciente al Estado español con base en esta misma interpretación del artículo $8 \mathrm{CEDH}$-en este caso referido al problema del ruido- tuvo lugar en el caso Moreno Gómez contra España (STEDH de I6 de noviembre de 2004).
} 
arriba, no debemos incurrir en la simplificación de considerar este caso como «revolucionario», pues hemos tenido ocasión de comprobar que se trata sólo de un paso lógico, aunque trascendente, en la trayectoria del TEDH y la Comisión.

En julio de I988 entró en funcionamiento en el municipio de Lorca (Murcia) una estación depuradora de desechos. A pesar de ello, la planta no contaba con el preceptivo permiso municipal exigido por el artículo 6 del Reglamento de Actividades Molestas, Insalubres, Nocivas y Peligrosas (Decreto 24I4/I96I, de 30 de noviembre ${ }^{\mathrm{I} 7}$ ). Gregoria López Ostra, vecina del municipio cuyo domicilio se encontraba a escasos metros de la estación depuradora, solicitó a las autoridades competentes el cierre de la misma, sin que sus pretensiones fueran atendidas. Por lo que, con fecha I3 de octubre de I988, interpuso recurso contencioso-administrativo contra el acto que permitía continuar en funcionamiento a la planta. Y fundó su recurso en el artículo I de la Ley 62/1978 de 26 de diciembre, sobre protección de los derechos fundamentales ${ }^{18}$, argumentando que los humos y olores que emanaban de la depuradora estaban ocasionando en su domicilio graves trastornos sobre su salud y la de su familia, al tiempo que provocaban la degradación ambiental de su entorno y de la calidad de su vida privada y familiar. Recordemos que la citada Ley 62/1978 instauró un procedimiento preferente y sumario para la protección judicial de los derechos y libertades fundamentales, cuando éstos hubiesen sido violados por actos o decisiones administrativas, en desarrollo de la previsión del art. 53.2 CE. Hoy este procedimiento se encuentra integrado en la Ley 29/1998, de I3 de julio, de la Jurisdicción Contencioso-Administrativa ${ }^{\mathrm{r} 9}$, y la Ley 62/1978 rige únicamente en lo no regulado por la nueva norma.

$\mathrm{Su}$ recurso fue desestimado en primera instancia en sentencia de 3I de enero de I989, tras lo cual interpuso recurso de apelación ante el Tribunal Supremo (io de febrero de I989). Sin embargo, éste fue nuevamente desestimado por sentencia de 27 de julio de I989, en la que el Tribunal Supremo determinó que, aún siendo grave la situación expuesta por la recurrente, no lo era en grado suficiente como para ser constitutiva de una violación de los derechos fundamentales amparados por la Constitución. Recaída esta sentencia, Gregoria López Ostra acudió a la última vía de que disponía en el ordenamiento interno: el recurso de amparo ante el Tribunal Constitucional. Dicho recurso fue presentado invocando la violación del artículo I5 CE (derecho a la integridad física), del artículo I8 (derecho a la vida privada y a la inviolabilidad del domicilio) y del artículo ig (derecho a elegir libremente su domicilio). Pero nuevamente el recurso fue desestimado, esta vez por manifiestamente infundado (Auto de 26 de febrero de I990). Concretamente, el Tribunal Constitucional advirtió que no era factible hablar de una violación de su derecho a la inviolabilidad del domicilio, ya que ningún agente o autoridad pública había penetrado en su hogar.

Hay que señalar que, paralelamente, dos miembros de la familia de la Sra. López Ostra acudieron a la vía contencioso-administrativa ordinaria en I989, y a la vía penal por la comisión de un hipotético delito ecológico, en I991. Caminos que resultaron en un primer término más efectivos que el emprendido por la primera recurrente, ya que en 1993 lograron que se acordara el cierre provisional de la estación depuradora en tanto se resolviera sobre su cierre definitivo. Por su parte, y ante la magnitud de las molestias padecidas, la Sra. López Ostra y su familia se trasladaron, en febrero de 1992, a un apartamento en el centro de la ciudad, corriendo con los gastos el Ayuntamiento de Lorca. Posteriormente, en I993, la recurrente se trasladó de nuevo a otra vivienda adquirida por la familia.

\footnotetext{
${ }^{17}$ BOE de 7 de marzo de I962.

${ }^{18}$ BOE de 3 de enero de I979.

${ }^{\text {r9 }}$ BOE de I4 julio de 1998 .
} 
Tras estos infructuosos intentos, la Sra. López Ostra decidió solicitar el amparo del Tribunal Europeo de los Derechos Humanos de Estrasburgo. Así, el I4 de mayo de I990, interpuso ante la Comisión Europea de los Derechos Humanos una demanda (núm. I6798/I990) dirigida contra el Estado español, argumentando que las molestias causadas por el funcionamiento de la estación depuradora suponían una injerencia ilegítima en varios de los derechos fundamentales amparados por el CEDH: el respeto de su vida privada familiar y a la tranquilidad del domicilio (art. 8) y la prohibición de tratos degradantes (art. 3). En decisión de 3I de agosto de I993, la Comisión estimó las pretensiones de la demandante en relación al art. 8, pero no respecto al art. $3 \mathrm{CEDH}$. En fecha de 8 de diciembre de 1993 el asunto llegó finalmente a manos del Tribunal. De forma sintética, los argumentos esgrimidos por la demandante y por los representantes del Gobierno español ante el TEDH fueron los siguientes ${ }^{20}$.

Por un lado, la demandante alegó la violación de los artículos 8 y 3 del Convenio a causa de los olores, ruidos y humos contaminantes provocados por la estación de depuración de aguas y residuos situada a escasos metros de su domicilio. Además, imputó la responsabilidad de dicha violación a las autoridades españolas, debido a la pasividad que habían demostrado en el cumplimiento de su deber de garantía de los derechos reconocidos en el CEDH. Por otro lado, el Gobierno español interpuso con carácter preliminar dos excepciones: el no agotamiento por la demandante de todas las vías de recurso internas (artículo 26 del Convenio) y la no cualidad de víctima por parte de la demandante del perjuicio invocado (artículo 25 del Convenio). En relación a la primera de ellas, el Gobierno alegó la existencia aún pendiente de la causa penal y contencioso-administrativa sobre el mismo asunto, aunque por actores distintos, y además el hecho de haberse escogido por la demandante la vía especial de la Ley 62/1978. El Gobierno entendió que esa vía no era la más indicada para esgrimir la supuesta violación al artículo I8 CE, ya que, como sostuvo el Tribunal Constitucional, no se había producido la entrada en su domicilio por parte de ningún funcionario público. Respecto a la segunda de las excepciones, la de la falta de la cualidad de víctima de la demandante, el Gobierno argumentó que la Sra. López Ostra había dejado de ser víctima de la supuesta violación del Convenio desde febrero de I992, fecha en la que ella y su familia fueron realojados en un apartamento del centro de la ciudad a cargo del Ayuntamiento de Lorca. Además, la demandante había cambiado de vivienda en I993, trasladándose a otro domicilio adquirido por la familia. Y, por último, el Gobierno advirtió que la estación depuradora había cesado en su funcionamiento en octubre de 1993 por mandato judicial. Además de las dos excepciones preliminares, en relación al fondo del asunto, el Gobierno argumentó la falta de entidad suficiente de las molestias padecidas por la recurrente, así como la ausencia de violación por el Estado español de las obligaciones derivadas del CEDH.

Como hemos reiterado, el Tribunal estimó las pretensiones de la demandante en relación a la violación del artículo 8 del Convenio. En primer lugar, el TEDH desestimó las excepciones planteadas por el Gobierno. Respecto al no agotamiento de los recursos internos, el Tribunal determinó que el recurso especial en protección de los derechos fundamentales es un medio eficaz y rápido para resolver las quejas planteadas, teniendo en cuenta que esos recursos planteados podrían haber conseguido el efecto querido, es decir, el cierre de la depuradora. En definitiva, el Tribunal entendió que la recurrente hizo uso de un recurso eficaz y pertinente, por lo que no estaba obligada a intentar también otros menos rápidos como el recurso contencioso ordinario, o la vía penal. Respecto a la segunda excepción, la que versaba sobre la cualidad de víctima de la demandante, el Tribunal la desestimó argumentado que fueron precisamente las malas condiciones ambientales las que forzaron el abandono del domicilio original. Y, además, que los sucesivos traslados no eliminan el hecho de que la recurrente y su familia sufrieron durante años dichas

\footnotetext{
${ }^{20}$ Seguimos en esta sistematización a GARCíA SAN JosÉ, D., op. cit., p. IIg6 a II99.
} 
condiciones. Para el TEDH, el dato de que, una vez cerrada la planta, la familia hubiese podido realojarse en su domicilio inicial, tiene valor únicamente a efectos de cuantificar el perjuicio sufrido por la demandante.

En relación al fondo del asunto, el pronunciamiento del TEDH versó sobre dos aspectos fundamentales: la gravedad y consecuencias de las molestias y la responsabilidad de las autoridades españolas. En relación al primero de ellos, el Gobierno había argumentado que las molestias no habían significado una incidencia en la salud de la familia con la entidad suficiente como para constituir una vulneración del Convenio, hecho que la Comisión había tenido ocasión de constar ${ }^{2 \mathrm{~T}}$. Sin embargo, el Tribunal no se pronunció de forma expresa sobre este punto, adoptando una posición que García San José califica de ecléctica ${ }^{22}$, en los siguientes términos:

«graves ataques sobre el medio ambiente pueden afectar al bienestar de una persona y privarla del derecho a la tranquilidad del domicilio, de manera que su vida privada y familiar pueden verse perjudicadas sin que se ponga en grave peligro su salud» (parágrafo 5I).

Este famoso pronunciamiento del Tribunal desliga la amenaza al bienestar personal en el domicilio por agresiones al medio de la amenaza por las mismas causas a la salud de las personas que habitan en el mismo. Significa, en definitiva, que para el análisis de la hipotética violación del artículo 8 en este tipo de supuestos, no es necesario discernir sobre si el ataque medioambiental ha incidido de forma suficiente o no sobre la salud de sus víctimas.

En relación al segundo de los aspectos centrales del fallo, el Tribunal no duda de la responsabilidad del Estado español por la pasividad demostrada por los poderes públicos competentes, que había contribuido a prolongar la grave situación en la que se vieron obligados a vivir los vecinos próximos a la planta durante tres años. El TEDH advierte que esas molestias no resultaron compensadas con el pago del alquiler del apartamento en el centro de la ciudad por el Ayuntamiento durante un año. En conclusión, el Tribunal estimó por unanimidad que hubo violación del artículo $8 \mathrm{CEDH}$ por parte del Estado.

Por último, en relación a la presunta violación del artículo 3 del Convenio (prohibición de tratos degradantes), el Tribunal coincidió con la Comisión al entender que las molestias padecidas por la demandante, aun siendo muy difíciles, no alcanzaban el grado necesario como para constituir la alegada violación del artículo 3 .

En aplicación del artículo 50 CEDH, se fijó una condena al Estado por los daños y perjuicios sufridos por la demandante, cifrados en torno a cinco millones de pesetas rebajando ostensiblemente la pretensión de veinticinco millones de la demandante- , además del abono de las costas del proceso.

Pero la jurisprudencia ambiental del TEDH y la Comisión no se detiene en el caso López Ostra, sino que tras él la línea hermenéutica del artículo 8 se ha visto reforzada y se han inaugurado nuevas tendencias jurisprudenciales. Así, el caso Stedh Buckley contra el Reino Unido (STEDH de 25 de septiembre de 1996) inauguró un grupo de casos en la más reciente jurisprudencia, referentes al conflicto de intereses entre asentamientos de población gitana y fines de protección ambiental. En el citado supuesto, la demandante

${ }^{21}$ La Comisión había podido analizar los informes técnicos presentados en la instrucción del proceso penal desarrollado ante la Audiencia Territorial de Murcia sobre la incidencia de las emanaciones provenientes de la planta depuradora sobre la hija de la demandante.

${ }^{22}$ GARCÍA SAN JOSÉ, D., op. cit., p. I999. 
había llevado un modo de vida itinerante en caravana de acuerdo con la tradición gitana, hasta que decidió instalarse de modo permanente en un terreno adquirido por ella en un área rural. Tras obtener una primera licencia temporal, se le denegó una posterior, al considerar las autoridades municipales que, de acuerdo con la normativa territorial y el plan de desarrollo local del área, la instalación de más asentamientos gitanos en la zona podría dañar la calidad del paisaje rural. El Tribunal de Estrasburgo, reconociendo que, efectivamente, la demandante había sufrido una interferencia en el ejercicio del derecho al respeto de la vida privada y familiar, consideró, sin embargo, que los medios empleados para garantizar el fin legítimo de protección del medio ambiente habían sido proporcionados. Como en el caso Pine Valley Developments LTD. y otros contra Irlanda, la tutela ambiental se otorgó desestimando las pretensiones de un particular.

En el año I99 8 se produjeron dos casos que consolidaron la doctrina recogida en el caso López Ostra en relación al artículo 8 del Convenio: McGinley y Egan contra el Reino Unido (STEDH de 9 de junio de I998 y, el que presenta mayor interés, Guerra $y$ otros contra Italia (STEDH de I9 de febrero de I998). Éste se suscitó a raíz de que unas vecinas de la localidad italiana de Manfredonia, cercana a una fábrica altamente contaminante, denunciaran el incumplimiento de la Directiva 82/50I/CEE (conocida como «Directiva Seveso»), relativa a los riesgos de accidentes graves relacionados con ciertas actividades industriales peligrosas para el medio ambiente y el bienestar de la población afectada, ya transpuesta al ordenamiento interno. Según las demandantes, existía una obligación de informar a cerca de los riesgos y medidas a adoptar en caso de accidente químico de la fábrica. Tras no obtener una resolución favorable en el ámbito interno, acudieron ante el TEDH ante una hipotética vulneración del artículo io del Convenio. El Tribunal europeo rechazó la argumentación planteada por las demandantes, señalando que la «libertad de recibir información» mencionada en el apartado 2 del art. Io del Convenio prohíbe que un gobierno impida a cualquier ciudadano recibir informaciones que otros consientan en facilitarles, pero no impone al Estado una obligación positiva, en situaciones como las del caso, a la difusión, motu proprio, de las informaciones. Sin embargo, el Tribunal recondujo el caso al ámbito del artículo 8, a pesar de que las actoras no habían formulado expresamente la demanda en tales términos. Recordando lo que en aquel momento era ya doctrina reiterada por el Tribunal y la Comisión, advirtió que atentados graves al medio ambiente pueden lesionar los derechos al disfrute del domicilio y de la vida privada y familiar de las personas. Concluyendo que, en el presente caso, el hecho de no haber facilitado a las demandantes la información ambiental -que les hubiese permitido evaluar los riesgos que podrían derivar para ellas como consecuencia de la actividad contaminante de la fábrica-, determinaba que el Estado hubiese fallado en su obligación de garantizar el derecho de las demandantes a su vida privada y familiar.

Este pronunciamiento del TEDH supone un evidente paso adelante en la ampliación de las exigencias de actuación positiva de los Estados para la garantía del artículo 8 del Convenio. Pero, al mismo tiempo, el Tribunal parece no mostrarse proclive a efectuar una ampliación semejante del ámbito de aplicación de otros derechos del Convenio, como el recogido en el artículo io.2.

El siguiente pronunciamiento del Tribunal con contenido medioambiental relevante se produjo en relación al asunto Chassagnou y otros contra Francia (STEDH de 29 de abril de I999). El caso se suscitó a raíz de la adopción por el Estado francés de la denominada «Ley Verdeille» que, junto con los objetivos de proteger el patrimonio cinegético mediante la defensa del medio ambiente y de la fauna frente a la caza sin control, incluía otras medidas como la creación de las denominadas Asociaciones Municipales de Caza Aprobadas (Associations communales de chasse agréés - ACCAs) y las Asociaciones Intermunicipales de Caza Aprobadas (Associations communales de chasse agréés - AICAs). El fin de estas asociaciones era el de reprimir la caza furtiva, el desarrollo de animales de caza y la educación cinegética. La Ley establecía la obligación de que los propietarios de áreas de 
superficie inferior a cierto umbral fuesen miembros de las Asociaciones y de permitir que en sus fincas se practicase la caza. Los demandantes, propietarios de fincas afectadas por la Ley y profundamente contrarios a la caza, acudieron a Estrasburgo alegando diversas violaciones en sus derechos fundamentales: el derecho a la propiedad, a la libertad de conciencia y pensamiento, la libertad de asociación negativa y el derecho a la igualdad (ya que la Ley eximía de las citadas obligaciones a los propietarios de grandes fincas).

El Tribunal dio la razón a los demandantes de forma contundente, estimando todas sus alegaciones. Según el TEDH, obligar por ley a un individuo a una adhesión profundamente contraria a sus propias convicciones y obligarle, por el hecho de esta adhesión, a aportar el terreno del que es propietario para que la asociación realice objetivos que él desaprueba, va más allá de lo que es necesario para garantizar un justo equilibrio entre intereses contradictorios. Por ello, las medidas acogidas por la «Ley Verdeille» no podían considerarse proporcionadas en relación al fin perseguido.

Este supuesto presenta el gran interés de que en él se enfrentan distintas ópticas sobre el medio ambiente, y por lo tanto sobre su forma de protección. Discrepancias que fueron puestas de manifiesto por los propios miembros del Tribunal a través de varios votos particulares.

El precedente del asunto Buckley contra el Reino Unido tuvo su continuación en un grupo de cinco recientes sentencias que comparten el mismo supuesto de hecho: la instalación por parte de familias gitanas de sus caravanas en áreas rurales del Reino Unido sin obtener la preceptiva licencia. Estos supuestos presentan un conflicto entre el derecho de las familias al respeto de su vida privada y familiar y al domicilio, y el interés general de la protección del medio ambiente, a través de la preservación de la calidad del paisaje. Este grupo de sentencias está compuesto por los asuntos Beard contra el Reino Unido, Chapman contra el Reino Unido, Lee contra el Reino Unido, Jane Smith contra el Reino Unido, y, el más importante de esta línea jurisprudencial hasta el momento, el asunto Coster contra el Reino Unido (todos ellos de i8 de enero de 200I). Realmente, existió un sexto caso, Varey contra el Reino Unido (Decisión de la Comisión de 2I de diciembre de 2000), en el que el TEDH no llegó a conocer sobre el fondo del asunto, al alcanzar el Estado un acuerdo amistoso con los demandantes.

Refiriéndonos al asunto Coster contra el Reino Unido, los demandantes, ciudadanos gitanos, habían llevado un modo de vida itinerante en caravana de acuerdo con la cultura y tradición gitanas. Al contraer matrimonio, decidieron asentarse con su vivienda móvil en varios lugares del municipio de Maidstone, siéndoles denegada su instalación en distintas ocasiones, ante lo cual se vieron obligados a aceptar una vivienda social fija. Sin embargo, los problemas de salud sufridos por los demandantes, consecuencia de sus dificultades para adaptarse a un modo de vida sedentario en un apartamento, animaron a los demandantes a adquirir un terreno en la localidad de Headcorn, para establecer en él su caravana. Una vez instalada su vivienda solicitaron la licencia municipal, que les fue nuevamente denegada, requiriéndoles las autoridades para que cesasen en el uso del terreno. Los señores Coster no cumplieron el requerimiento, y fueron condenados a sanciones de multa. El Inspector urbanístico argumentó que, si bien era consciente de que llevar una vida sedentaria producía a los gitanos toda una serie de problemas de inadaptación y enfermedades, pues no es su modo habitual de vida, por otro lado, el establecimiento de la caravana en el lugar elegido constituía una intrusión real en el paisaje rural que le rodeaba, capaz de estropear seriamente el carácter y la apariencia de dicho lugar, lo que era contrario a los objetivos de los planes de ordenación locales. Por lo tanto, las autoridades locales decidieron que el interés de tipo general sobre la calidad del paisaje debía prevalecer sobre el interés particular de la familia gitana. Ante ello, la familia intentó instalarse en un nuevo emplazamiento, adoptando una serie de medidas para reducir el impacto visual producido por la caravana, pero su solicitud de licencia fue de nuevo denegada por motivos estéticos. 
Una vez agotados los cauces internos para hacer valer sus pretensiones, el señor y la señora Coster acudieron ante la Comisión Europea alegando una violación de su derecho al respeto de la vida privada y familiar y su domicilio, de su derecho al respeto de los propios bienes (artículo I del Protocolo núm. I), y, como consecuencia directa de lo anterior, una violación del derecho a la instrucción de sus hijos (artículo 2 del Protocolo núm. I). La razón es que las sucesivas medidas de ejecución por las autoridades locales británicas les habían impedido garantizar un hogar estable, que permitiese a sus hijos asistir regularmente a la escuela. Alegaron, además, una violación del artículo I4 CEDH, asegurando que han sido discriminados por su condición gitana.

El fallo del Tribunal contiene algunas cuestiones de gran interés para el estudio que nos ocupa, especialmente en relación al artículo 8 CEDH. Por un lado, y haciendo suya la doctrina sentada por la Comisión en el caso Buckley, el TEDH constató que la vida en caravana es parte integrante de la identidad gitana, y que, además, ese domicilio está perfectamente amparado por lo dispuesto en el artículo 8 del Convenio. En el caso precedente, la Comisión había advertido ya que no hay nada en el artículo 8 del Convenio que permita deducir que sólo se debe respeto al domicilio legalmente establecido ${ }^{23}$. Este caso supone, por tanto, una nueva ampliación en la aplicación del artículo 8. En lo que ahora nos interesa, implica que cualquier particular podrá hacer valer su derecho al respeto del domicilio frente a amenazas al medio ambiente, independientemente de la situación legal en la que el mismo se encuentre, es decir, con independencia del título jurídico en virtud del cual habite en dicho espacio.

Por otro lado, respecto a la existencia de una injerencia en el derecho de los señores Coster amparado por el artículo 8, el Tribunal manifestó una discrepancia con el argumento expresado en la demanda. El TEDH sostuvo que fueron las medidas de ordenación y ejecución adoptadas frente a los demandantes los que provocaron tal injerencia, pero no la legislación en la materia, como afirmaron en su demanda. Según el Tribunal, la legislación en materia de ordenación no impedía a los afectados seguir el modo de vida gitano, ni les obligaba a aceptar un alojamiento clásico, y en definitiva, no incriminaba el estilo de vida de la minoría gitana. La injerencia procedía, entonces, de los actos de aplicación de esa normativa. Sin embargo, como hemos visto anteriormente, el hecho de que exista una intromisión en los derechos fundamentales no implica necesariamente que ésta sea ilegítima. Por ello, el Tribunal abordó de nuevo el análisis de la posible aplicación del párrafo segundo del artículo 8 , tratando de determinar si las medidas adoptadas por las autoridades británicas reunían todos los requisitos para estar amparadas por dicho precepto. Según la doctrina del Tribunal, para que así sea, las medidas deberían estar previstas por la ley, perseguir un fin legítimo y ser necesarias en una sociedad democrática. El TEDH concluyó que, en efecto, las medidas de ejecución de la normativa respetaban tales exigencias: el interés general en la preservación del entorno (representado en este caso por el respeto al paisaje natural) constituía un fin legítimo, las medidas sin duda estaban amparadas por la Ley, y, además, respetaban el principio de proporcionalidad $^{24}$. Si bien el Tribunal había entendido que la ilegalidad del domicilio no impedía la aplicación del artículo 8 a favor de los demandantes, esa situación de

\footnotetext{
${ }^{23}$ Recogido por BouAZZA ARIÑO, O., op. cit., p. I80 (nota a pie núm. I8).

${ }^{24}$ En realidad, respecto a la proporcionalidad de las medidas, que refleja el criterio de su necesidad en una sociedad democrática, el Tribunal aplica habitualmente el criterio del «estándar nacional», permitiendo que la ponderación de intereses encontrados se efectúe por las autoridades nacionales, en razón de su más directo conocimiento de las circunstancias del caso. Vid. Ibídem, p. 185. En el apartado siguiente tendremos ocasión de analizar esa aplicación del «estándar nacional» por parte del Tribunal en relación a la aplicación del art. 8 CEDH como vía para la protección del ambiente.
} 
irregularidad sí fue determinante a la hora de baremar los intereses en conflicto, que es en definitiva el sustrato de todo juicio de proporcionalidad. Así, el TEDH afirmó que

«cuando el domicilio ha sido establecido ilegalmente en un lugar dado, la persona que discute la legalidad de un orden está en una posición menos fuerte. El Tribunal será algo reticente a conceder protección a las personas que desafiando a sabiendas las prohibiciones de la Ley, establecen su domicilio en un lugar cuyo entorno está protegido. Si el Tribunal actuara de otra manera, alentaría las acciones ilegales en detrimento del derecho de los otros miembros de la comunidad a que se proteja el medio ambiente».

De este pronunciamiento podemos extraer la importante conclusión de que, para el Tribunal, el paisaje es un interés que se sitúa plenamente dentro del bien jurídico medio ambiente en un plano de igualdad con cualquier otro interés contenido en el mismo; en definitiva, con la suficiente entidad como para justificar limitaciones en los derechos individuales de los particulares. En nuestra opinión éste es un importante paso en la ampliación del concepto de medio ambiente defendido por el Tribunall ${ }^{25}$, ya que, no lo olvidemos, el paisaje no está configurado estrictamente por el ambiente en sentido físico, entendido como el conjunto de condiciones físico-químicas adecuadas (ya sea para el desarrollo de la vida, o la salud, o la vida privada y familiar, etc.), sino que significa la percepción humana subjetiva de ese entorno. Con ello no queremos restar importancia al factor estético como condición del bienestar humano, pero sí poner de manifiesto que, al hablar de paisaje, nos situamos en un plano cualitativamente distinto y que, por tanto, el Tribunal ha ensanchado los límites de su idea de ambiente.

En definitiva, en el asunto Coster el TEDH sostiene que no se ha producido violación del artículo 8 del Convenio, y tampoco de los restantes derechos alegados por los demandantes. Sin embargo, la decisión fue adoptada por tan sólo diez votos contra siete. En su voto particular común, los siete jueces en desacuerdo apreciaron que el Estado británico, concretamente las autoridades locales implicadas, habían incurrido en un incumplimiento de sus obligaciones positivas para garantizar el respeto de la vida privada y del domicilio de la minoría gitana, al no haber adoptado las medidas necesarias para proporcionar un emplazamiento adecuado a la familia Coster (teniendo además en cuenta la carencia de espacios adecuados para tales emplazamientos en el Estado británico).

Vemos que el voto particular de los siete jueces no discute la idea de medio ambiente manejada por la sentencia, ni la ponderación realizada en la misma entre intereses individuales y colectivos (de tipo medioambiental). La discrepancia se centra, más bien, en el alcance de las obligaciones positivas que para los Estados parte emanan del Convenio.

Finalizaremos este recorrido por la ya extensa jurisprudencia ambiental del TEDH citando una importante resolución condenatoria del Tribunal, que se inscribe en el grupo de supuestos de las molestias causadas por los grandes aeropuertos. Se trata del asunto Hatton y otros contra el Reino Unido (STEDH de 2 de octubre de 200I). Se trata, de nuevo, de vecinos residentes en las cercanías al aeropuerto de Heathrow, que acudieron al Tribunal de Estrasburgo alegando que el ruido de los vuelos nocturnos les estaba ocasionando graves trastornos del sueño, que implicaban una vulneración de su derecho al respeto del domicilio y de la vida privada y familiar. Concretamente, argumentaban la insuficiencia del sistema de cuotas sonoras de los vuelos nocturnos establecido en I993 por la Secretaría de Estado de Transportes para reducir el ruido perturbador del sueño. La gran novedad de esta

\footnotetext{
${ }^{25}$ Sin duda el Tribunal hace suyas las tendencias dominantes en la legislación europea, que en los últimos años han dado un gran protagonismo al paisaje.
} 
sentencia radica en que, por primera vez dentro de esta línea jurisprudencial, el Tribunal falló condenando al Estado. Su argumentación se basó en la insuficiencia de estudios realizados para establecer el sistema, tanto por lo que respecta al interés económico que revisten para la nación los vuelos nocturnos, como en lo referente al impacto de los mismos en el descanso de los recurrentes. Así, el Tribunal afirmó que

«en ausencia de un estudio previo y completo dirigido a la búsqueda de la solución menos onerosa en relación a los derechos humanos, no es posible aceptar que al tener en cuenta los efectos negativos en los intereses económicos del país -los cuales en sí mismos no han sido cuantificados- el Gobierno haya logrado el justo equilibrio al establecer el sistema de $1993^{26}{ }^{26}$.

Este fallo supone un avance en su jurisprudencia, en la medida en que detalla el nivel de exigencia en la actuación pública para hacer valer el párrafo segundo del art. 8 en relación al criterio del interés económico nacional. Por lo que podemos afirmar que se aprecia una voluntad en el Tribunal de elevar los requisitos para su aplicación.

Por último, y como ya advertimos antes, esta sentencia ha sido invocada por quienes sostienen que, a través de su jurisprudencia ambiental, el Tribunal ha venido a reconocer el derecho subjetivo a un medio ambiente adecuado. Y ello, en base a que en su pronunciamiento el Tribunal se refiere a los derechos medioambientales como «una nueva generación de derechos humanos», y la alusión a la Carta de Derechos Fundamentales de la Unión Europea, en la que parece reconocerse dicho derecho subjetivo.

\section{Líneas transversales de la protección indirecta del ambiente en la jurisprudencia del TEDH y la Comisión}

El repaso a la jurisprudencia ambiental del TEDH y la Comisión efectuado en el apartado anterior demuestra que estos órganos hacen uso de una doble vía interpretativa del CEDH para la protección indirecta del ambiente. Por un lado, utilizan la técnica del efecto reflejo, cuando una violación de alguno de los derechos reconocidos en el Convenio es causada por un ataque medioambiental. Encontramos un ejemplo claro en el caso López Ostra. Por otro lado, cuando las autoridades públicas de un Estado parte establecen una limitación en el goce de alguno de los derechos del Convenio que así lo permitan (concretamente, los artículos 8, 9, iо y II CEDH), sobre la base de la protección del medio ambiente, como sucedió, por ejemplo, en los casos Pine Valley Developments y Coster.

Con esa perspectiva global abordaremos en este punto el análisis de las líneas generales o transversales que subyacen toda esa jurisprudencia ambiental, con el fin de extraer el sentido de la tutela otorgada por el TEDH y la Comisión al entorno con base en el Convenio.

a. Posibles vías para la tutela indirecta del medio a partir de la jurisprudencia ambiental del TEDH y la Comisión.

En la jurisprudencia del Tribunal y la Comisión podemos detectar que, al menos siete preceptos del Convenio, suponen, siquiera potencialmente, una vía adecuada para la

\footnotetext{
${ }^{26}$ Traducción tomada de LozAno CuTANDA, B., op. cit., p. I94.
} 
protección indirecta del medio ambiente. Se trata de vías interpretativas por las que el Tribunal entiende que los intereses medioambientales se encuentran inmersos en el Convenio, ya que su garantía es imprescindible para la protección de ciertos derechos amparados expresamente por el CEDH.

a.I. Derecho al respeto de la vida privad y familiar e inviolabilidad del domicilio ${ }^{27}$.

El TEDH y la Comisión han utilizado de dos formas distintas el artículo 8 como vía para la protección indirecta de intereses de tipo medioambiental. En los supuestos análogos al asunto López Ostra, se utiliza el párrafo primero como limitación a inmisiones exteriores. Por otro lado, en los casos similares al asunto Coster, el Tribunal y la Comisión emplean el segundo párrafo para justificar una limitación del derecho a la intimidad frente a superiores intereses ambientales.

En relación al párrafo primero, hemos visto que los órganos de Estrasburgo han afirmado que daños o deterioros producidos en el ambiente pueden afectar al bienestar de las personas y, por tanto, suponer un ataque a la vida privada de los perjudicados y a su derecho a disfrutar del domicilio. Por lo que, sensu contrario, el goce efectivo en el derecho al respeto del domicilio implica el derecho a vivir en un medio ambiente sano. Hemos visto también que el Tribunal y la Comisión han tenido ocasión de pronunciarse en este sentido frente a la incidencia de diferentes focos de contaminación: por ruidos, por la contaminación general del aire y de las aguas por una planta de depuración, etc. Por su parte, el párrafo segundo ha servido al Tribunal para fundar la necesidad de subordinar, en ciertos casos, los intereses individuales frente a los colectivos de tipo ambiental. De este aspecto concreto nos ocuparemos más adelante.

La aplicación del artículo $8 \mathrm{CEDH}$, sobre todo de su párrafo primero, es sin duda la principal vía empleada hasta el momento por el Tribunal y la Comisión para justificar su tutela del medio. Lo que ha motivado que ésta sea la corriente dentro de su jurisprudencia ambiental más estudiada por la doctrina, que ha generado en algunos autores, sobre todo a raíz del asunto López Ostra, enormes expectativas sobre la potencialidad de esta vía de actuación. Sin embargo también hay quienes, en un análisis quizá más sosegado, han puesto de manifiesto los peligros y limitaciones de esta labor hermenéutica. Así, Velasco Caballero ha denunciado lo que considera un «exceso judicial», cometido por el Tribunal al extender la inviolabilidad domiciliar hasta el concepto de «calidad de vida». Para el citado autor, en modo alguno se pierde privacidad por el mero hecho de vivir en un ambiente hediondo o molesto; ello podrá afectar a bienes jurídicos relacionados con la salud, pero no a la intimidad de $\operatorname{los}$ afectados ${ }^{28}$. A nuestro juicio, a estas afirmaciones no les falta parte de razón. En muchas ocasiones las agresiones al entorno afectan negativamente a la salud de las personas que lo habitan, y siendo esta consecuencia más grave que la posible violación de la intimidad domiciliaria, tal afección debería apreciarse de forma preferente. Pero, como

\footnotetext{
${ }^{27}$ Artículo $8 \mathrm{CEDH}$ : Derecho al respeto a la vida privada y familiar.

I. Toda persona tiene derecho al respeto de su vida privada y familiar, de su domicilio y de su correspondencia.
}

2. No podrá haber injerencia dela autoridad pública en el ejercicio de este derecho, sino en tanto en cuanto esta injerencia esté prevista por la ley y constituya una medida que, en una sociedad democrática, sea necesaria para la seguridad nacional, la seguridad pública, el bienestar económico del país, la defensa del orden y la prevención del delito, la protección de la salud o de la moral, o la protección de los derechos y las libertades de los demás.

\footnotetext{
${ }^{28}$ Velasco CABAllero, F., «Protección del medio ambiente ante el Tribunal Europeo de Derechos Humanos», Revista Española de Derecho Constitucional, 45, septiembre i995, p. 3II y 3I2.
} 
veremos después, paradójicamente el Tribunal se ha mostrado reacio a la aplicación de la protección de la salud personal en supuestos relacionados con agresiones al ambiente. Teniendo esto presente, sin embargo, consideramos que las conclusiones de Velasco Caballero son demasiado taxativas. Como sostuvo el Tribunal en el asunto López Ostra, puede considerarse que, efectivamente, existen agresiones al medio que afectan a la vida privada y familiar de las personas, sin que supongan necesariamente una agresión contra su salud. Aunque, quizá, habría que aclarar tal afirmación en el sentido de que, obviamente, una agresión ambiental que incida en el ámbito domiciliario hasta el punto de provocar una infracción del artículo $8 \mathrm{CEDH}$, necesariamente afectará en alguna medida a la salud de quienes habiten en ella, al menos en el plano psicológico. Pero lo que el Tribunal pone de manifiesto es que es posible que dicha afección a la salud no sea de la entidad suficiente como para suponer una vulneración del artículo 2 del Convenio. Con ello, el TEDH parece establecer que el nivel de intensidad de una acción contaminante del medio necesario para afectar a la salud de las personas, en el sentido del artículo 2 CEDH, es superior al necesario para transgredir el párrafo primero del artículo 8. Posteriormente nos referiremos a la conveniencia o inconveniencia de mantener esta postura.

Por su parte, y también a raíz del asunto López Ostra, Huelin Martínez de Velasco ha advertido el peligro de que, del contenido otorgado por el TEDH y la Comisión al artículo 8 , llegue a deducirse que el mencionado precepto se infringe siempre que una acción $u$ omisión administrativa sea la causa de ruidos, malos olores, emanaciones, etc. que perturben la vida privada y familiar en el domicilio ${ }^{29}$. Lo cual significaría, según este autor, una desmesurada ampliación de su ámbito de protección, que conduciría a una situación de hipertrofia, y en definitiva a la imposibilidad de su reconocimiento por saturación. Sin embargo, el propio autor advierte de que ese peligro es hoy por hoy una mera posibilidad teórica, ya que el Tribunal, por el momento, ha dejado claro que no cualquier inmisión es idónea para producir la mencionada vulneración; es necesario que, además, quede roto el justo equilibrio que debe existir entre el interés general y el del titular del derecho. No obstante, en nuestra opinión, y como analizaremos en el subapartado siguiente, hasta ahora el problema ha sido más bien el contrario. Podría considerarse que el Tribunal ha otorgado un campo de actuación excesivamente amplio al apartado segundo del artículo 8 como vía para hacer prevalecer supuestos intereses colectivos de tipo económico. Precisamente, Navarro Gómez alude a ese factor como una de las grandes carencias de la técnica de aplicación del artículo $8 \mathrm{CEDH}$ con fines de preservación ambiental. Advierte que, en realidad, el Tribunal sólo ha sancionado violaciones de este tipo cuando los daños producidos al medio ambiente son particularmente graves, y además no están justificados por cuestiones de interés general ${ }^{30}$.

29 Huelin Martínez De Velasco, J., «Intimidad personal y familiar, domicilio y medio ambiente», en VV.AA., Perfiles del derecho constitucional a la vida privada $y$ familiar, Madrid: Escuela Judicial/CGP, I996, p. 267.

${ }^{30}$ NAVARRo GómEZ, C., «La protección del medio ambiente en el marco del Convenio Europeo de Derechos Humanos», en VV.AA., I Congreso Nacional de Derecho Ambiental, Sevilla, abril 1995, Cima Medio Ambiente, Valencia: I996. p. 204. 
a.2. Derecho a la propiedad privada y al disfrute de los propios bienes ${ }^{31}$.

La limitación del derecho a la propiedad privada para la protección de intereses generales no supone ninguna novedad. Se trata de la llamada «función social de la propiedad», consagrada en muchos textos constitucionales de nuestro entorno, como en la propia Constitución española de I978 en su artículo 33.2. No hay ninguna dificultad para considerar que, entre los intereses colectivos a los que apunta dicha función social, se encuentran los de tipo medioambiental. Es frecuente que, en los ordenamientos internos, razones ambientales justifiquen la transformación de ciertas dependencias objeto de propiedad privada en dominio público, así como la privación singular de ciertos bienes a sus propietarios originarios. En el ordenamiento español encontramos dos claros ejemplos de esta técnica en las ampliaciones de la demanialidad efectuadas por la Ley de Aguas 29/1985 de 2 de agosto ${ }^{32}$, en materia de aguas continentales, y por la Ley de Costas 22/1988 de 28 de julio ${ }^{33}$, que suponen la conexión de los artículos 45, I32 y 32.2 CE. En definitiva, éste es el tipo de razonamiento detentado por el TEDH en el asunto Pine Valley contra Irlanda, en el que las pretensiones de los demandantes, fundadas en la transgresión de su derecho al disfrute de sus bienes, resultó justificada en aras de la protección de superiores intereses ambientales que constituían causa de interés general.

Sin embargo, la faceta más novedosa atribuida por el TEDH y la Comisión al derecho de propiedad privada es la de su defensa, en lugar de su limitación, como vía para la protección indirecta del medio. A través de pronunciamientos como el del asunto Chassagnou $y$ otros contra Francia o el del asunto Zander contra Suecia, el Tribunal y la Comisión han advertido que el ambiente y el derecho de propiedad pueden ser entendidos como intereses interrelacionados, e incluso inherentes, por lo que puede considerarse que el primero se encuentra implícito en el reconocimiento de la propiedad por el Convenio. Se razona así que los daños ambientales producidos en un bien pueden ser de tal magnitud, y los cambios operados en él por causa de la contaminación pueden ser de tal entidad, que afecte al valor del bien y desvirtúe el derecho a su propiedad, al constituir una especie de «expropiación parcial» $»^{34}$. En el ordenamiento interno español, esta forma de uso del derecho de propiedad ha sido utilizada desde hace tiempo por el Tribunal Supremo, basándose principalmente en los deberes derivados de las relaciones de vecindad reguladas por el Código civil $^{35}$. Si bien, en muchos de esos supuesto, la protección del ambiente ha sido una

${ }^{31}$ Protocolo adicional número I, Artículo I. Protección de la propiedad.

Toda persona física o moral tiene derecho al respeto de sus bienes. Nadie podrá ser privado de su propiedad más que por causa de utilidad pública y en las condiciones previstas por la Ley y los principios generales del derecho internacional.

Las disposiciones precedentes se entienden sin perjuicio del derecho que poseen los Estados de poner en vigor las Leyes que juzguen necesarias para la reglamentación del uso de los bienes de acuerdo con el interés general o para garantizar el pago de los impuestos u otras contribuciones o de las multas.

${ }^{32}$ BOE de 8 de agosto de i985.

${ }^{33}$ BOE de 29 de julio de I988.

${ }^{34}$ NAVARro GómEZ, C., op. cit., p. 204.

35 La doctrina iusprivatista ha indicado cuatro diferentes vías que, de acuerdo con nuestro ordenamiento civil, permiten una protección indirecta del ambiente:

- Relaciones de vecindad (art. 590 Cc.): posibles denuncias basadas en la realización de actividades molestas o contaminantes sin respeto a las distancias exigidas por el Cc, infracción de los usos permitidos en un determinado inmueble, no adopción de las debidas precauciones, etc.

- Responsabilidad contractual: por ejemplo, supuestos de compraventa de terrenos contaminados, que podría generar para el vendedor la obligación de saneamiento ex art. I46r Cc., o 
consecuencia no buscada directamente por el Tribunal español, sin duda este interés está presente de forma implícita en este tipo de casos.

No obstante -y frente a la conclusión sostenida en los últimos tiempos por autores de adscripción neoliberal, en el sentido de que la propiedad privada y el libre mercado son en realidad las medidas proteccionistas más adecuadas ${ }^{36}-$, la defensa de la propiedad privada como posible vía para la protección del medio ambiente habrá de ser necesariamente, en nuestra opinión, una excepción ante la regla general que sugiere la necesidad de limitar ese derecho para garantizar la protección de los ecosistemas.

que podría generar responsabilidad por vicios o defectos ocultos ex art. I474 Cc. En relación con el arrendamiento, la posibilidad de resolución del contrato ante la realización de actividades notoriamente incómodas por el resto de los vecinos (art. II4.8 de la Ley 29/1994, de Arrendamientos Urbanos). O, también la posibilidad de aplicación del art. I554.3 Cc. Ante la causación de ruidos por parte del arrendador, que supondría la violación de la obligación de mantener al arrendatario en el goce pacífico de la cosa arrendada.

- Responsabilidad extracontractual (art. I902 Cc.): esta vía cedería en caso de que el supuesto pudiese ser catalogado como una relación de vecindad, pero será aplicable cuando ésta no exista, o cuando efectivamente se hayan respetado las exigencias del art. $590 \mathrm{Cc}$.

- Abuso de derecho (art. 7.2 Cc.), como principio general informador del ejercicio del derecho de propiedad.

Este tema ha sido abordado en profundidad por RodRíGueZ RUIZ DE VILLA, D., «La protección civil indirecta del medio ambiente», en La Ley: Revista jurídica española de doctrina, jurisprudencia $Y$ bibliografía, I992, Vol. 3., pp. 880-9I4 y MATIEs GARCíA, J., «La responsabilidad civil en los suelos contaminados», en VV.AA., I Congreso Nacional de Derecho Ambiental, Sevilla, abril 1995, Cima Medio Ambiente, Valencia, I996. pp. 455-462.

No podemos perder de vista que, no obstante, el carácter marcadamente individualista del sistema de responsabilidad civil encuentra en la práctica grandes obstáculos para la reparación de los daños ocasionados al medio ambiente, sobre todo cuando se trate de proteger intereses de carácter colectivo o difuso. Sin embargo, y pese a estas dificultades, el Tribunal Supremo sí viene reconociendo el derecho a ser indemnizado ante los daños provocados por agresiones al ambiente, cuando la ilicitud de la conducta y la relación de causalidad entre la acción u omisión y el daño causado pueden ser probados adecuadamente. De hecho, el rastro de esta línea jurisprudencial se remonta a varias décadas. Las principales resoluciones en la materia hasta la fecha son las siguientes: STS I4 de mayo de I963, STS 30 de octubre de I963, STS de i2 de diciembre de ig8o, STS de I7 de marzo de I98I, STS de I4 de julio de I982, STS de 3i de enero de 1986, STS de 3 de diciembre de I987, STS de I3 de junio de I988, STS de I6 de enero de I989, STS de 37 de octubre de I990 y STS de 2 de febrero de 200I. Esta jurisprudencia presenta interesantes operaciones interpretativas por parte del Tribunal, como por ejemplo la extensión del concepto «humos» del art. I908 Cc. a cualquier emisión o inmisión procedente de actividades contaminantes, aunque excedan notablemente del sentido estricto del término, como en los supuestos de emisiones de polvo, de vertidos contaminantes a cauces fluviales, o la producción de ruidos. Se trata en definitiva de la adaptación a la nuevas realidad social de una norma, el Código civil, de más de cien años de antigüedad.

${ }^{36}$ Se trata del denominado neoliberalismo ambiental o ecología de mercado, doctrina construida sobre los cimientos de la teoría neoliberal de F. A. Hayek, y que postula la no adopción de medidas correctoras ni el establecimiento de ningún tipo de límite a la iniciativa privada para la preservación del ambiente. Al contrario, busca fortalecer la propiedad privada y la libertad de iniciativa empresarial como principios absolutos, para así lograr la protección del ambiente. Estas teorías no introducen en realidad ninguna novedad respecto a la teoría neoliberal clásica, limitándose a poner de manifiesto nuevas virtudes, ahora de tipo ecológico, de sus tradicionales pautas mercantilistas y privatizadoras. Buena parte de sus esfuerzos se dirige a negar cualquier competencia pública en la protección del ambiente. Para una descripción y defensa de la ecología de mercado véase, por ejemplo, LARAIN, HurTADO, y RAmíreZ, Ecología de Mercado, Fundación Libertad y Desarrollo-Trineo S.A., Santiago de Chile: I995 o SMITH, J., Ecología de Mercado, Fundación para el análisis y los estudios sociales, Madrid: 1996. 


\section{a.3. Derecho a la vida ${ }^{37}$.}

Hemos indicado antes que uno de los pronunciamientos más importantes del Tribunal en el asunto López Ostra fue la consideración de los intereses de la particular sin necesidad de que se hubiese producido un daño para su salud o la de su familia. Las críticas contra esta postura se han dirigido a afirmar que, precisamente, un atentado contra el medio podría afectar a la salud de las personas, pero nunca a su intimidad domiciliaria. Aunque, tal y como argumentamos, esa afirmación puede resultar excesiva, hemos podido comprobar que el Tribunal ha situado el nivel de incidencia de un atentado contra el ambiente sobre la salud muy por encima al de su afección a la intimidad personal y familiar para entender infringido el Convenio. Parece que el TEDH entiende que una agresión al medio ambiente es susceptible de violar -en el sentido del Convenio- de forma más directa la vida personal y familiar de las personas que su derecho a la salud. Hasta el momento, el Tribunal ha hecho una interpretación restrictiva del derecho a la vida del art. 2 CEDH.

Esta conclusión se ve amparada por la decisión del Tribunal en relación al asunto Guerra y otros contra Italia. En este caso, el TEDH circunscribe la violación de los derechos reconocidos por el Tratado a los referentes al respeto de la vida privada y familiar y del domicilio que reconoce el art. $8 \mathrm{CEDH}$. Sin embargo, las emanaciones sobre las que giraba el supuesto habían provocado daños físicos de gravedad, además de posibles muertes por causas laborales de trabajadores. Y, pese a ello, el TEDH no llegó a vincular la protección del derecho a la salud y a la integridad física al derecho a la vida del artículo 2 . Bien es cierto que, como advierte Lozano Cutanda, «el art. 2 CEDH tiene un alcance mucho más restrictivo en su formulación que el art. I5 CE, ya que no contempla como este último el derecho a la integridad física y moral $\gg^{38}$. Sin embargo, entendemos que no existe ningún obstáculo técnico para que el Tribunal y la Comisión, por vía interpretativa, extendiesen el derecho a la vida a la protección de las personas, no únicamente frente a la muerte, sino frente a toda afección, eso sí, de cierta gravedad, que amenace en mayor o menor medida su existencia. No tiene por qué entenderse de una ampliación excesiva del ámbito de aplicación del artículo 2, sobre todo si tomamos en consideración la labor hermenéutica desarrollada por el Tribunal en torno al artículo 8. De hecho, el juez P. Jambrek, se pronunció en ese sentido en su voto particular a la sentencia Guerra y otros contra Italia:

«Parece llegado el momento a la jurisprudencia del Tribunal consagrada al artículo 2 de evolucionar, de desarrollar los derechos que se deducen implícitamente del mismo, de definir las situaciones que conllevan un riesgo real y grave para la vida o los diferentes aspectos del derecho a la vida».

El propio magistrado califica la decisión del Tribunal en aquel supuesto de «ocasión perdida». No podemos dejar de lado el hecho de que, ciertamente, las dificultades probatorias de la relación de causalidad entre un atentado contra el ambiente y un perjuicio concreto para la salud son muchas veces elevadas, y en algunos casos insalvables. Lo cual ha sido comprobado reiteradamente en el ordenamiento español en vía penal, ante los intentos

${ }^{37}$ Artículo 2 CEDH. Derecho a la vida.

I. El derecho de toda persona a la vida está protegido por la Ley. Nadie podrá ser privado de su vida intencionadamente, salvo en ejecución de una condena que imponga pena capital dictada por un tribunal al reo de un delito para el que la ley establece esa pena.

${ }^{38}$ LOZANO CUTANDA, B., op. cit., p. I93. El artículo i5 de la Constitución española se expresa en los siguientes términos: «Todos tienen derecho a la vida y a la integridad física y moral, sin que, en ningún caso, puedan ser sometidos a tortura ni a penas o tratos inhumanos o degradantes. Queda abolida la pena de muerte, salvo lo que puedan disponer las leyes penales militares para tiempos de guerra». 
de imputación del subtipo agravado de delito ecológico (art. 325 CP in fine, que eleva la pena del tipo básico cuando exista riesgo de grave perjuicio para la salud de las personas), o la apreciación de un concurso ideal entre el delito ecológico y un delito de lesiones, o incluso de homicidio imprudente -en casos en los que llegaron a producirse resultados lesivos o de muerte, respectivamente-. Sin duda, el Tribunal encuentra más sencillo imputar al Estado la violación del derecho a la vida privada y familiar que el derecho a la vida o la salud de los particulares. Pero tampoco podemos dejar de advertir que la situación de deterioro de los ecosistemas, a todos los niveles y escala casi global, implicaría considerar la gravedad de las reiteradas agresiones al medio en toda su amplitud, sin obviar ninguna de sus implicaciones. Y, más aún, que razones de simplicidad técnica u oportunidad política no pueden llevar a dejar de lado sus consecuencias más dramáticas, como las afecciones a la vida y la salud.

a.4. Prohibición de tratos degradantes y de la tortura ${ }^{39}$.

En estrecha relación con lo que acabamos de analizar en relación al artículo 2 CEDH, el Tribunal y la Comisión tampoco se han mostrado proclives, por el momento, a apreciar la violación de la prohibición de tratos degradantes amparada por el Convenio derivada de injerencias contra el ambiente. Sin embargo, García San José aprecia una sensible evolución en este sentido en la sentencia López Ostra, ya que fue la primera ocasión en la que el Tribunal llegó a decidir sobre una pretendida violación del artículo 3 en relación a un ataque medioambiental ${ }^{40}$. Con anterioridad, la Comisión había declarado este tipo de supuestos inadmisibles por incompatibilidad ratio materiae con el Convenio. Sobre este particular, el Tribunal se expresó en la mencionada sentencia en los siguientes términos:

«Aunque difíciles, las condiciones en las que la demandante ha sido obligada a vivir, las cuales constituyen por otro lado un ataque al artículo 8 del Convenio, no comportan un nivel de gravedad tal para que pudieran ser consideradas como constitutivas de un trato contrario al artículo 3 del Convenio».

Para el Tribunal, los tratos prohibidos por el artículo 3 CEDH han de ser de una magnitud suficiente como para alcanzar, al menos, el grado mínimo de trato degradante, algo que en el caso López Ostra, a su juicio, no llegó a suceder. Sin embargo, a través de su decisión, el Tribunal viene a reconocer que el artículo 3 es uno de los derechos cuyo contenido puede resultar violado a consecuencia de una agresión sobre el medio ambiente. No debemos olvidar que las demandas fundadas en violaciones del artículo 8, a consecuencia de afecciones ambientales, fueron declaradas inadmisibles por la Comisión hasta el asunto Arrondelle contra el Reino Unido (I980), y que, a pesar de ello, la primera sentencia condenatoria con base en dicho argumento no se produjo hasta el asunto López Ostra (I994). Quizá en el futuro el Tribunal esté dispuesto a desarrollar una evolución semejante en relación al artículo 3 CEDH.

\footnotetext{
${ }^{39}$ Artículo 3 CEDH. Prohibición de la tortura.

Nadie podrá ser sometido a tortura ni a penas o tratos inhumanos o degradantes.

${ }^{4 \circ}$ GarCía SAN José, D., op. cit., p. I210 y i2iI.
} 
a.5. Libertad de información (en materia ambiental ${ }^{4 \mathrm{t}}$.

El derecho a la información en materia ambiental ha adquirido en los últimos años un creciente protagonismo ${ }^{42}, y$, sin duda, se trata de un derecho de gran importancia y de una indudable potencialidad para evitar actuaciones contrarias al equilibrio de los ecosistemas. El oscurantismo en los asuntos referentes a la gestión ambiental favorece la impunidad en las agresiones ilícitas contra el medio. Por el contrario, la circulación de información eleva necesariamente el nivel de diligencia de los agentes con responsabilidades en la materia, y supone una poderosa arma en manos de los particulares para controlar, tanto la acción de los poderes públicos (desplazando su voto de confianza), como de las empresas y corporaciones privadas (desplazando sus pautas de consumo).

Sin embargo, el TEDH tampoco se ha mostrado proclive, por el momento, a extender la interpretación del artículo io en ese sentido. Al respecto, debemos referirnos de nuevo al asunto Guerra y otros contra Italia. Vimos que, en el mismo, el Tribunal excluyó la posibilidad planteada por la Comisión -recogida después en los fundamentos de la Sentencia-, de que del artículo io CEDH pudiera derivarse la obligación para los Estados miembros, no sólo de posibilitar el acceso al público a las informaciones en materia de medio ambiente, sino también de elaborar y difundir aquellas informaciones que, por su propia naturaleza, no podrían llegar de otra forma al conocimiento del público. Como apunta acertadamente Lozano Cutanda, ello hubiese permitido hacer jugar al CEDH «un papel preventivo respecto a violaciones potenciales del Convenio en caso de atentados graves contra el medio ambiente, pues esta disposición entraría en juego antes incluso de que hubiera una lesión directa a otros derechos fundamentales -como el derecho a la vida o el respeto de la vida privada y familiar $\rightarrow{ }^{43}$. Significaría dar entrada en el Convenio, por esta vía, al principio de prevención, criterio angular del Derecho ambiental y de una gran virtualidad práctica. No obstante, esta solución continúa siendo una mera posibilidad de la que el Tribunal no ha hecho uso por el momento.

${ }^{41}$ Artículo Io CEDH. Libertad de expresión.

I. Toda persona tiene derecho a la libertad de expresión. Este derecho comprende la libertad de opinión y la libertad de recibir o de comunicar informaciones o ideas, sin que pueda haber injerencia de autoridades públicas y sin consideración de fronteras. El presente articulo no impide que los Estados sometan a las empresas de radiodifusión, de cinematografía o de televisión a un régimen de autorización previa.

${ }^{42}$ En el ámbito de la Unión Europea, fue aprobada la Directiva 90/3I3/CEE, sobre el derecho de acceso a la información en materia ambiental, transpuesta -aunque con bastante retraso- al ordenamiento español por Ley 38/1995 de I2 de diciembre (BOE de I3 de diciembre).

${ }^{43}$ LOZANO CUTANDA, B., op. cit., p. I96. 


\section{a.6. Derecho a un proceso equitativo ${ }^{44}$.}

Aunque este derecho nos sitúa en el plano procesal, ha sido alegado ante el Tribunal en referencia a derechos del Convenio que se habían visto afectados a consecuencia de atentados contra el ambiente. Tal es el caso, por ejemplo, del asunto Zander contra Suecia, y, en cierta medida, del asunto Powell y Rayner contra el Reino Unido.

\section{a.7. Adopción de medidas cautelares por parte de la Comisión.}

Hemos señalado que, en el asunto Guerra, el Tribunal no extendió las obligaciones positivas de los Estados en relación al art. Io CEDH hasta el punto de exigirles la difusión de informaciones de relevancia ambiental. Y que, con ello, se perdió quizá una buena ocasión para dar entrada al principio de prevención en la aplicación del Convenio.

El principio de prevención se encuadra en los llamados principios estructurales del Derecho ambiental, que orientan a cerca de cuáles deben ser los instrumentos más idóneos para lograr el fin de la protección ambiental. Junto con el mencionado, se sitúan el principio causal y el principio de integración de los costes ambientales (que conlleva el principio de corrección de los costes al medio ambiente y el principio «quien contamina paga»). Debe destacarse que el principio de prevención es fundamental en la actuación ambiental, debido al alto potencial de irreparabilidad de los daños ambientales. Imbuido en el mismo encontramos el subprincipio de cautela o precaución, con base en el cual puede limitarse una actividad potencialmente peligrosa para el medio, aún sin haber sido probada exhaustivamente la relación causa efecto ${ }^{45}$.

Pero, sin duda, la forma más directa por la que -en este caso la Comisión- podría dar entrada al principio de prevención -o, en su caso, más específicamente, al de precaución-, es la adopción de medidas cautelares. El art. 36 del Reglamento interno de la Comisión permite a este órgano la adopción de tales medidas para la protección de los derechos del recurrente cuando, por las circunstancias del caso, la espera a la resolución final del asunto pudiera provocar un daño de gran magnitud o incluso irreparable en los mismos.

Sin embargo, el TEDH ha visto con recelo estas medidas, y sólo han sido puestas en marcha de, forma excepcional, en algunos casos relativos a órdenes de expulsión del

\footnotetext{
${ }^{44}$ Artículo 6 CEDH. Derecho a un proceso equitativo.

I. Toda persona tiene derecho a que su causa sea oída equitativa, públicamente y dentro de un plazo razonable, por un tribunal independiente e imparcial, establecido por la ley, que decidirá los litigios sobre sus derechos y obligaciones de carácter civil o sobre el fundamento de cualquier acusación en materia penal dirigida contra ella. La sentencia debe ser pronunciada públicamente, pero el acceso a la sala de audiencia puede ser prohibido a la prensa y al público durante la totalidad o parte del proceso en interés de la moralidad, del orden público o de la seguridad nacional en una sociedad democrática, cuando los intereses de los menores o la protección de la vida privada de las partes en el proceso así lo exijan o en la medida considerada necesaria por el tribunal, cuando en circunstancias especiales la publicidad pudiera ser perjudicial para los intereses de la justicia.

${ }^{45}$ En este sentido, el Principio I4 de la Declaración de Río de 1992 indica que «cuando haya peligro de daño grave o irreversible, la falta de certeza científica absoluta no deberá utilizarse como razón para postergar la adopción de medidas eficaces en función de los costos para impedir la degradación del medio ambiente». Sobre el principio de prevención, véase ORTEGA ÁlvarEZ, L. (dir.), Lecciones de Derecho del Medio Ambiente, Valladolid: Lex Nova, 2000 ( $2^{\mathrm{a}}$ ed.), p. 5 I y 52; y MARTín MAteo, R., Manual de Derecho Ambiental, Pamplona: Aranzadi, 2003, p. 48 y 49, entre otros.
} 
territorio naciona ${ }^{46}$. La aplicación de medidas cautelares ha sido denegada en muchos otros casos, entre ellos, en el asunto Powell y Ryner contra el Reino Unido. Por lo que podemos concluir que el Tribunal no está dispuesto, por el momento, a dar entrada al mencionado principio por vía interpretativa en el CEDH en el campo que nos ocupa.

b. Aplicación de las cláusulas de limitación de los derechos fundamentales y el margen de apreciación estatal.

Aunque, tradicionalmente, las declaraciones de derechos fundamentales han buscado proteger con la máxima amplitud los intereses que pretendían amparar, éstos suelen aparecer complementados mediante el establecimiento de una serie de límites. Se trata de supuestos excepcionales que persiguen el respeto hacia los derechos de los demás a través de una cierta restricción de los individuales. A diferencia de otras declaraciones de derechos, el CEDH ha optado por incluir un segundo párrafo en un conjunto de preceptos (concretamente el 8, derecho a la vida privada y familiar; 9, libertad de pensamiento, conciencia y religión; io libertad de expresión; y iı, derecho de reunión y asociación, así como en los Protocolos adicionales), estableciendo esas limitaciones excepcionales al ejercicio de los derechos ${ }^{47}$.

La consecuencia de estas restricciones es que, como hemos indicado más arriba, aún en casos en los que los particulares hayan sufrido inmisiones insoportables no resulte infringido el Convenio. Ese juicio variará en función de toda una serie de requisitos que el Tribunal y la Comisión han ido desarrollando en su jurisprudencia, y que se dirigen a garantizar un adecuado equilibrio entre intereses individuales y colectivos. El principio fundamental que los órganos de Estrasburgo han acogido en esta materia es la atribución de un amplio margen de apreciación a los Estados parte en la adopción de las medidas conducentes a mantener ese equilibrio. Este criterio del «estándar nacional» enlaza con la doctrina del Tribunal y la Comisión según la cual la obligaciones de los Estados en relación al Convenio no se limitan a actuaciones de tipo negativo, sino que abarcan aquellas medidas positivas necesarias para garantizar su efectividad. La atribución de este margen de actuación a los Estados es, en definitiva, una autolimitación judicial del Tribunal, justificada, por un lado, por el carácter subsidiario del Convenio, y, por otro, por la presunción del mejor conocimiento de la realidad interna referente a cada caso por parte de los Estados ${ }^{48}$. El TEDH advierte que en modo alguno le corresponde sustituir con su criterio el de las autoridades nacionales en los distintos ámbitos de la política estatal. Por lo que su intervención se limita a la facultad de control.

Tomar en consideración este criterio dota de coherencia interna a diversas resoluciones del Tribunal en las que, pese a la discrepancia en el fallo, existe una identidad de razonamiento. Así, en el caso Powell y Rayner la desestimación de las pretensiones de los demandantes se basó en la estimación de que las medidas adoptadas por el Estado fueron suficientes para garantizar el equilibrio entre los intereses particulares (de tipo ambiental), de los demandantes y de los colectivos (de tipo económico) del conjunto del país. El

${ }^{46}$ Por ejemplo, en el asunto Soering contra el Reino Unido (STEDH de 7 de julio de I989) estas medidas se adoptaron para evitar que el Estado demandando extraditara al recurrente a Estados Unidos, donde previsiblemente sufriría los efectos del «corredor de la muerte», lo que podía constituir un trato contrario al artículo $3 \mathrm{CEDH}$.

${ }^{47}$ Por ejemplo, la Carta de Derechos Fundamentales de la Unión Europea adopta otra técnica legislativa, dedicando un único precepto (art. 52.I) a los límites de los derechos.

${ }^{48}$ CARrillo Donaire, J.A., y GalÁn Vioque, R., op. cit., p. 278. 
Tribunal entendió que las decisiones del Estado se movieron dentro de su legítimo margen de apreciación para establecer la prevalencia de intereses en el caso concreto, que le otorga el artículo 8.2 $\mathrm{CEDH}^{49}$. Sin embargo, en el caso López Ostra el Tribunal entendió que la pasividad del Estado en la protección de los derechos de la demandante había roto el equilibrio entre intereses individuales y generales, por lo que el Estado había excedido el margen de apreciación basado en el párrafo sengundo del artículo 8, y por lo tanto había infringido el Convenio. En conclusión, discrepancia de fallos pero identidad de razón en su fundamentación.

De hecho, y a pesar de la progresión en la consideración de intereses ambientales indirectamente amparados por el CEDH, el Tribunal se había mostrado reticente a imputar responsabilidades a los Estados por injerencias en el medio que supusieran a su vez una infracción del Convenio. Ello había sido justificado, en la mayoría de los casos, con base en la aplicación del artículo 8.2 y a la concesión de un amplio margen de apreciación estatal para priorizar generales intereses de economía nacional frente a las pretensiones individuales de protección de la vida privada y familiar, e indirectamente de protección ambiental. Así, en el asunto Powell $y$ Ryner el Tribunal sostiene en su sentencia:

«Como ha señalado la Comisión en sus resoluciones sobre la admisibilidad, la existencia de grandes aeropuertos internacionales, incluso en zonas urbanas muy pobladas, y el incremento del empleo de los aviones de reacción se han hecho indudablemente necesarios para el bienestar económico del país. Según estadísticas no discutidas facilitadas por el Gobierno, el aeropuerto de Heathrow, uno de los más utilizados del mundo, tiene extraordinaria importancia en el comercio y las comunicaciones internacionales y en la economía del Reino Unido. Los propios demandantes reconocen que la explotación de un aeropuerto de estas condiciones persigue un fin legítimo y que no se pueden suprimir totalmente las repercusiones desfavorables en su entorno» (parágrafo 42). «Hay que tener en cuenta el equilibrio justo que debe existir entre los intereses concurrentes del individuo y del conjunto de la sociedad» (parágrafo 4I).

El Tribunal subordinó la protección individual basada en cuestiones ambientales a la economía nacional en diversas situaciones más, como en el asunto G. $\gamma$ E. contra Noruega, relativa a los perjuicios causados por la construcción de una gran presa a la población autóctona lapona.

Esta postura denota, a nuestro juicio, una falta de voluntad por parte del Tribunal a la hora de incidir en los grandes proyectos o infraestructuras estatales, cuyo beneficio en términos económico-crematísticos es alto, pero cuya lesividad en relación al medio indudablemente también lo es. Lo que conlleva serias carencias de enfoque en esa primera jurisprudencia ambiental del TEDH y la Comisión en su pretensión de incluir implícitamente los intereses ecológicos en el Convenio. Enfoque que, en realidad, puede considerarse erróneo no sólo desde el punto de vista ecológico, sino incluso económico. En este sentido, no siempre es claro que la existencia de una empresa o instalación

\footnotetext{
${ }^{49}$ En este caso, la decisión del Tribunal vino determinada por las diversas medida adoptadas por las autoridades públicas británicas para tratar de reducir el impacto del ruido de los aviones en las zonas próximas al aeropuerto, pese a que éstas no consiguieron eliminar las graves molestias padecidas por los vecinos. También tuvo una influencia decisiva el hecho de que, como afirma el propio Tribunal, las medidas anti-ruido adoptadas por el Estado coincidieran con las del Convenio de Roma de I952 sobre los daños que causan las aeronaves extranjeras en la superficie. Parece que el respeto al justo equilibrio de intereses viene reforzado en virtud de la adopción por el Estado de criterios de protección que cuentan con el respaldo de la comunidad internacional. Puede encontrarse una enumeración detallada de estas medidas en MARTIN-RETORTILLO BAQUER, L., «El ruido de los grandes aeropuertos...», op. cit., p. I30.
} 
contaminante sea interesante para la economía nacional, dato que el Tribunal da por supuesto en las resoluciones mencionadas. Rodríguez Ruiz De Villa alude, por ejemplo, a los gastos sanitarios derivados para la Estado -y en definitiva para la economía del país- de la existencia de focos de elevado impacto ambiental, a las jubilaciones anticipadas por ese motivo, al número de personas que fallecen por causa de estas circunstancias, o a la disminución y desaparición de producciones agrícolas por esa causa. Concluyendo que, probablemente, si se sopesasen esos y otros factores «no estaría tan claro dónde está el interés de la economía nacional. Por ello, esa contraposición entre desarrollo económico y

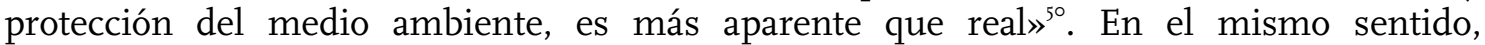
Riechmann ha advertido que, si al hacer las cuentas del crecimiento económico se contabilizaran -realmente- , incluso de manera muy imperfecta y parcial los «costes externos» de tipo social y, sobre todo, ambiental, «resultaría que en nuestra actual economía del despilfarro llevamos ya mucho tiempo menguando en lugar de creciendo» ${ }^{5 \mathrm{I}}$.

En este tipo de pronunciamientos, el Tribunal realiza implícitamente un balance entre desarrollo económico y protección medioambiental argumentando a favor del primero, aún cuando hoy parece posible afirmar sin miedo a incurrir en un discurso meramente ideológico que, la idea de desarrollo económico ilimitado, justificado en sí mismo sin atender a su impacto en otros valores o intereses -que son considerados meras «externalidades»- es el fundamento conceptual y práctico de la actual situación de degradación ambiental ${ }^{52}$.

Sin embargo, el asunto López Ostra parece haber supuesto un punto de inflexión en este criterio del Tribunal. Por un lado, el asunto Guerra y otros contra Italia supuso una nueva condena al Estado a consecuencia de una injerencia contra el entorno. Pero, sobre todo, dos pronunciamientos desde entonces denotan una apreciable evolución en la

$5^{\circ}$ Rodríguez Ruiz De Villa, D., «La protección civil indirecta del medio ambiente», La Ley: Revista jurídica española de doctrina, jurisprudencia y bibliografía, I992, Vol. 3., p. 898.

${ }^{51}$ Según cálculos de la propia OCDE, a mediados de los años noventa la tasa de crecimiento económico general de los países industrializados habría disminuído entre el 3 y el 5\% si se restasen los costes de contaminación (tan sólo los de contaminación) generada junto con el producto social. En este sentido, véase RIECHMANN, J. «Desarrollo sostenible: la lucha por la interpretación», en VV.AA., De la economía a la ecología, Madrid: Trotta y Fundación I ${ }^{\circ}$ de Mayo, I995, p. 29 y 30 . En una fundamentación más abstracta, y sobre la base de la crítica que, ya en el siglo XIX, autores como Geddes, Podolinsky y Soddy plantearon ante la despreocupación de los economistas neoclásicos respecto del marco biofísico en el que se inscribe la economía humana, Georgescu-Roegen ha planteado un enfoque de la economía mucho más acorde con las leyes de la termodinámica, presentándola como un flujo entrópico dentro de un sistema abierto a la entrada de energía, frente a la noción circular del proceso económico, como sistema cerrado desde el punto de vista energético, sostenido por los economistas clásicos. Véase al respecto GeORGESCU-ROEGEN, N., La Ley de la Entropía y el Proceso Económico, Madrid: Fundación Argentaria: I996.

${ }^{52}$ La teoría económica capitalista nació sobre el postulado básico -forjado en los siglos XVIII y, sobre todo, XIX- de la posibilidad de un incremento del nivel de producción continuo e ilimitado. En relación a la naturaleza -a la cual el proceso económico, obviamente, no puede escapar-, esta posibilidad fue afirmada a través de dos premisas: la reducción de la naturaleza, o partes aprehensibles de la misma, a bienes de intercambio mercantil; y la consideración de los daños ambientales ocasionados por el proceso productivo como efectos externos o externalidades en relación al mismo. Esta teoría se remonta a creación en los años veinte del concepto de deseconomía externa por Pigou, como definición de la diferencia entre el coste privado y el coste social de las actividades económicas. Si el primero expresa el coste que debe soportar un agente económico para lograr la producción, el segundo hace referencia al coste que soporta el conjunto de la sociedad a consecuencia de dicha producción. Los daños ambientales se incluirían entre estos daños a terceros. A partir de ahí, la doctrina capitalista considera erróneamente que todo efecto externo pueda recibir una valoración económica suficientemente justificada. 
sensibilidad ecológica del Tribunal y la Comisión: los asuntos Coster contra el Reino Unido y Hatton $y$ otros contra el Reino Unido.

En el primero de ellos, como vimos, el Tribunal declara legítima la injerencia del Estado británico en diversos derechos de una familia gitana amparados por el Convenio, ante la negativa de concesión de permisos para la instalación de la vivienda móvil de ésta en diversos emplazamientos. Y ello, en base a que el TEDH considera que las medidas adoptadas por el Estado contemplaban el fin legítimo que constituye la protección de los «derechos ajenos» por medio de la defensa del medio ambiente, no considerando necesario analizar si entran también en juego otros objetivos (parágrafo 96 de la STEDH de 18 de enero de 200I). Es decir, el Tribunal no considera necesario analizar la concurrencia de otras posibles causas, por ejemplo de tipo económico, para analizar si el balance de intereses efectuado por el Estado se mantuvo dentro de los límites permitidos por el Convenio, bastando la concurrencia de un interés ambiental atendible. Es más, como vimos antes, el Tribunal acoge un concepto decididamente expansivo de ambiente al basar su decisión en intereses meramente paisajísticos. Probablemente, el hecho de que esta sentencia supone un giro en el enfoque del Tribunal venga corroborado por el hecho de que siete de sus miembros emitiesen un voto particular a la decisión final. En éste, los jueces disidentes afirmaban que, a pesar del margen de apreciación en manos del Estado, en este caso las autoridades británicas no encontraron el equilibrio justo entre el bienestar económico del país y el disfrute del derecho de los demandantes al respeto de sus domicilios y de sus vidas privadas y familiares. Opinión que parece situarse más bien en la línea del criterio sostenido por el Tribunal hasta ese momento.

El asunto Hatton supuso la primera sentencia condenatoria al Estado por las molestias causadas por el aeropuerto de Heathrow tras un número considerable de demandas desestimadas, lo que es de por sí indicativo de una clara variación de criterio. No debemos extraer conclusiones precipitadas en el sentido de un cambio revolucionario en el juicio valorativo del Tribunal, pues no olvidemos que éste basó su decisión en la insuficiencia de estudios realizados por el Estado respecto a la injerencia que la actividad del aeropuerto suponía en los derechos de los demandantes. Pero sí encontramos en el razonamiento del TEDH elementos que confirman la aparente evolución del Tribunal en la ponderación entre intereses económicos y ambientales. Concretamente, en el parágrafo 97 de la STEDH de 2 de octubre de 200I, el Tribunal afirma que:

«(...) al intentar encontrar el equilibrio correcto, los Estados deben tener en cuenta todo el conjunto de consideraciones materiales. Además, en un campo tan sensible como el de la protección medioambiental, la mera referencia al bienestar económico del país no es suficiente para superar los derechos de los demás».

El pronunciamiento parece superar la automaticidad del juicio del interés general de una determinada actividad por el mero hecho de su rentabilidad económica. Lo que, implícitamente, expresa quizá la intención de recomponer el equilibrio entre desarrollo económico y protección ambiental.

Este giro jurisprudencial, a nuestro con una gran potencialidad de desarrollo futuro, ha sido, sin embargo, criticado desde algún sector de la doctrina. En este sentido, Lozano Cutanda ${ }^{53}$ ha incidido en la ausencia de cualquier referencia a la idea de la gravedad de la lesión o limitación producida en los derechos de los recurrentes como criterio previo y determinante de una posible vulneración del artículo 8 CEDH en la sentencia Hatton. Advierte que, la ausencia de elementos de análisis alegada por el Tribunal para realizar el balance entre los intereses en juego, conlleva asimismo la ausencia de una prueba

\footnotetext{
${ }^{53}$ LOZANO CUTANDA, B., op. cit., p. I95.
} 
fehaciente de la gravedad de las lesiones infligidas a los recurrentes. Algo que, a su entender, debería operar en cada caso concreto como requisito previo ineludible para proceder al análisis del juicio ponderado realizado por el Estado. En este sentido, el juez Brian Kerr, en su voto particular a la sentencia, había sostenido que

«el caso López Ostra no puede llevar a establecer un principio general en virtud el cual el interés económico nacional es un factor que debe ser siempre desatendido o que debe siempre someterse a la necesidad de proteger el derecho al respeto de la ida y familiar, especialmente si la lesión a éstos resulta periférica e ilusoria».

La citada autora advierte que, de seguir este criterio, se «corre el riesgo de acabar por desvirtuar los procedimientos extraordinarios establecidos para la protección de los derechos fundamentales (...) al confundirlos con las meras reclamaciones de responsabilidad patrimonial de la Administración por el funcionamiento de sus servicios públicos», lo que en modo alguno contribuiría a la mejora del bien jurídico ambiental, pretendiendo únicamente una compensación económica por el perjuicio individual padecido $^{54}$. Siendo éste un riesgo cierto y que potencialmente podría presentarse, en nuestra opinión es demasiado pronto para realizar esta denuncia. Sobre todo teniendo en cuenta que, después de este giro jurisprudencial, el Tribunal no ha tenido aún ocasión de pronunciarse en ningún supuesto que verse sobre algún macroproyecto estatal de gran impacto ecológico, de donde podría deducirse de forma fehaciente hasta qué punto está dispuesto el Tribunal a restringir intereses económicos nacionales supuestamente concurrentes.

c. La tensión entre intereses individuales y colectivos.

El análisis que acabamos de realizar denota una constante tensión entre intereses de tipo individual y colectivo, ambos de tipo ambiental y económico, según los casos. Las decisiones del Tribunal y la Comisión se inclinaron en favor de unos u otros en los distintos casos analizados. Este hecho podría resultar sorprendente si tenemos en cuenta que el CEDH protege esencialmente derechos humanos de la primera generación, y, por lo tanto, de carácter marcadamente individual. Es principalmente a través de las cláusulas de restricción de los derechos fundamentales como el Convenio permite la entrada de intereses de tipo supraindividual. Debemos trasladar esta reflexión al plano de la protección ambiental. Más arriba tuvimos ocasión de comprobar la complejidad del bien jurídico medio ambiente, al que catalogamos como referencial o en blanco por el hecho de estar integrado por múltiples intereses, tanto de tipo individual como colectivo. Cabe preguntarse, por tanto, qué enfoque adopta el TEDH y la Comisión con respecto a la protección del medio ambiente, si de tipo estrictamente individual o más bien colectivo.

En este sentido, algunos autores han advertido un efecto paradójico en la relación entre derechos individuales y colectivos en la sentencia López Ostra. En el caso concurren dos niveles distintos de intereses ambientales: uno individual, el de la Señora López Ostra al respeto de su vida personal y familiar, y otro colectivo, de la generalidad del municipio en disfrutar de una planta depuradora de residuos. El efecto paradójico derivaría del hecho de que, del sentido de la sentencia, pudiera deducirse una prevalencia del interés individual frente al general en una materia como el medio ambiente que, si bien presenta elementos pertenecientes a ambas dimensiones, tiene un marcado talante colectivo. Martín Mateo ha advertido que «late en la sentencia una óptica individualista del medio ambiente (atentados

\footnotetext{
${ }^{54}$ Ibídem.
} 
personalizados y en el domicilio) que no es la que más se acomoda a la naturaleza colectiva de los intereses medioambientales» ${ }^{55}$. En efecto, parece que el avance en la protección jurídica del ambiente exige más el reconocimiento de legitimaciones colectivas amplias y frente a daños no individualizados, la tutela de los intereses difusos, etc., que redundar en protecciones de tipo estrictamente individual. Para Ruiz Rico, la doctrina defendida en el fallo del Tribunal Europeo es incluso potencialmente contradictoria con los fines de conservación ambiental, dado que «en el fondo, el Tribunal no hace sino defender a toda costa -y diríamos más, a un precio antiecológico a la postre- la típica esfera de autonomía individual frente a la injerencia o intervencionismo público; o, lo que es lo mismo, considera prevalente en todo caso el derecho particular sobre el interés o beneficio social» ${ }^{56}$.

Sin embargo, tal y como ha respondido otro sector de la doctrina, la paradoja o la contradicción es sólo aparente. El Tribunal no basa su decisión en el la defensa a ultranza de la esfera individual de protección, sino en el juego que en toda su jurisprudencia otorga al margen de apreciación en manos del Estado respecto al equilibrio de intereses. Un equilibrio cuyo control por el TEDH se basa en lo que, Jimena Quesada y Tomás Mallén, han denominado «medidas reprochables» ${ }^{57}$. El equilibrio cederá a favor de los intereses colectivos perseguidos por la actuación estatal siempre que no se consiga mediante medidas reprochables, tal y como sucedió en el caso López Ostra, donde el juicio reprochabilidad derivó de la pasividad de las autoridades públicas.

Podríamos decir que, indudablemente, el Tribunal parte de una protección indirecta del ambiente de corte individual, ya que cualquier pretensión esgrimida ante el TEDH debe estar basada en alguno de los derechos del Convenio, que son mayoritariamente personales. Aludiendo a la representación ideal del bien jurídico medio ambiente que esbozamos más arriba, el Tribunal parte de los círculos centrales del concepto. La expansión de la protección hacia círculos exteriores - donde se sitúan intereses colectivos- exige que, bien no se vulneren los intereses situados en las zonas anteriores, o bien que su vulneración se realice mediante medidas no reprochables, de acuerdo con los criterios del Tribunal.

En contra de la opinión de Ruiz Rico sobre la hipotética defensa por el Tribunal de un núcleo individual inmune frente a la intervención pública, en nuestra opinión la sentencia ofrece una visión más positiva si entendemos que, más que defender lo individual frente a la injerencia pública, lo que se hace es reconocer que la injerencia pública (o su inactividad) es precisamente la causante de graves daños ambientales, lo cual desgraciadamente sucede a menudo. Idea que viene reforzada por la sentencia Coster, en la que el Tribunal sostuvo precisamente que el medio ambiente, como interés legítimo a proteger en nuestra sociedad, debe prevalecer en determinados supuestos sobre los derechos individuales de los particulares (en ese caso, el derecho al respeto de su vida privada y familiar).

\footnotetext{
${ }^{55}$ MARTín MATEO, R., «Avances en la efectividad de la responsabilidad ambiental», en MORENO Martínez (coord.), Perfiles de la responsabilidad civil en el nuevo milenio, Madrid: Dykinson, 2000, p. 230.

${ }^{56}$ RUIZ RICO, G., El derecho constitucional al medio ambiente (dimensión jurisdiccional), Valenci:, Tirant lo Blanch, 2000, pp. III y II2.

${ }^{57}$ JIMENA QUESADA , L. y TOMÁS MALLÉN, B.S., op. cit., p. $2 \mathrm{I} 63$ y $2 \mathrm{I} 64$.
} 
d. El hipotético reconocimiento del derecho fundamental a un medio ambiente adecuado por el TEDH y la Comisión.

La habitual polémica entre la doctrina española, sobre la existencia en nuestro ordenamiento del derecho subjetivo a un medio ambiente adecuado, ha sido trasladada al ámbito del Convenio Europeo de Derecho Humanos con ocasión de la jurisprudencia ambiental del TEDH y la Comisión. Varios autores, y no sólo en la doctrina española, han considerado que esta jurisprudencia ha venido a reconocer de forma progresiva un derecho fundamental al medio ambiente. Así, Sudre ha sostenido de forma contundente que la sentencia López Ostra ha consagrado el derecho a un medio ambiente sano como un derecho individual protegido por el Convenio, por la vía del derecho al respeto del domicilio garantizado por el artículo $8 \mathrm{CEDH}^{58}$. Esa sentencia habría reconocido el medio ambiente como un derecho fundamental de nueva generación, doctrina que habría sido confirmada por la resolución del caso Costner, donde el Tribunal sitúa el medio ambiente en el mismo plano de protección que otros derechos fundamentales ${ }^{59}$.

A nuestro juicio, tales afirmaciones resultan quizá excesivas. Con Huelín Martínez de Velasco -si bien éste se pronuncia en relación al ordenamiento interno español-, no podemos dejar de lado que «las categorías jurídicas son lo que son o, lo que es lo mismo, lo que el ordenamiento jurídico quiere que sean» ${ }^{60}$. En este sentido, algunas opiniones, más que a un análisis estricto del ordenamiento, parecen responder a deseos de lege ferenda o consideraciones en el plano del deber ser. Las evidentes carencias materiales del sistema de protección del ambiente configurado por el TEDH y la Comisión por vía interpretativa que hemos ido apuntando, y que después recopilaremos y ampliaremos, hacen difícil sostener que nos encontramos ante la aplicación de un verdadero derecho fundamental al medio ambiente. Su reconocimiento supone inevitablemente afirmar que existe un derecho subjetivo a vivir en unas condiciones medioambientales sanas en manos de los particulares que pueda ser directamente alegado ante los Tribunales, en este caso ante el TEDH. Y no podemos olvidar que, en todo momento, el Tribunal sólo otorga una protección al ambiente de tipo indirecto o colateral. Bien es cierto que, como hemos sostenido, el medio ambiente es un bien jurídico atravesado por múltiples intereses. Pero una cosa es afirmar una violación al derecho a un medio ambiente adecuado de un particular -que es un interés legítimo en un plano axiológico y debería ser una realidad tangible en el plano jurídicopositivo- y como consecuencia otra serie de derechos del cual ese particular es titular apreciando una especie de concurso de infracciones- , y otra muy distinta es sostener, como hace el Tribunal, que el efectivo respeto a ciertos derechos individuales - derecho a la vida privada y familiar, etc.- implica que éstos se desenvuelvan en condiciones medioambientales sanas, por lo que, lógicamente, éstos podrían verse afectados por una injerencia contra el ambiente. En un nivel más práctico, la primera afirmación implicaría que los particulares podrían acudir ante el Tribunal esgrimiendo directamente una violación de su derecho a un medio ambiente adecuado, algo que chocaría con una

${ }^{58}$ SUDRE, F., «Chronique de la jurisprudence de la Cour européenne des droits de l'homme I994», Revue Universelle des Droits de l’Homme, vol. 7, 4-6, junio de I995, p. II2. En el mismo sentido, JIMENA QueSADA, L. Y TOMÁs MALlÉN, B.S., op. cit., p. 2i6o. Para CARRILlo DonAIRE, J.A., y GALÁn VIOQUE, R., op. cit., p. 272, en la sentencia López Ostra el TEDH ha concedido de forma mediata y por la puerta de atrás la carta de naturaleza a nivel europeo al derecho a un medio ambiente adecuado.

${ }^{59}$ En este sentido, vid. BouAZZA ARIÑO, O., op. cit., p. I90 y I9I (nota a pie $n^{\circ} 29$ ), que llega a esta conclusión tras advertir que, en el asunto Costner, el Tribunal argumenta que el medio ambiente, como interés general, es un motivo suficiente y pertinente para justificar una injerencia en los derechos fundamentales de la persona, concretamente en el derecho al respeto de la vida privada y familiar.

${ }^{60}$ Huelin Martínez De Velasco, J., op. cit., p. 262. 
incompatibilidad ratio materiae con el Convenio. Cualquier pretensión planteada ante la Comisión deberá fundarse en un derecho expresamente reconocido por el CEDH.

En este sentido, si acudimos a la definición de derecho subjetivo acuñada por Castán Tobeñas, podemos entender por tal «la facultad o conjunto de facultades con significado unitario e independiente, que se otorga por el ordenamiento jurídico a un ser de voluntad capaz o de voluntad suplida por la representación, para la satisfacción de sus fines o intereses, y autoriza al titular para obrar válidamente, dentro de ciertos límites, y exigir de los demás, por un medio coactivo, en la medida de lo posible, el comportamiento

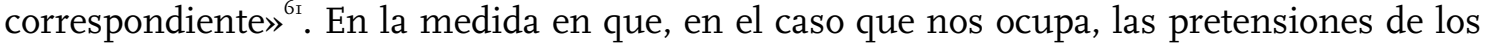
particulares irían dirigidas frente al Estado, el medio ambiente constituiría un derecho público subjetivo. Sin embargo, el medio ambiente no constituye hoy por hoy una facultad con significado unitario e independiente en el marco del Convenio, en la medida en que siempre deberá ser alegado en conexión a algún otro derecho de tipo individual.

Además, el reconocimiento de un auténtico derecho fundamental al medio ambiente por vía jurisprudencial choca con otros obstáculos que podríamos calificar de tipo «político», pues tal actuación del TEDH y la Comisión supondría que estos órganos, de tipo jurisdiccional, estarían sustituyendo el papel legislador del Consejo de Europa. Ello no sólo es cuestionable desde el punto de vista técnico-jurídico, sino también probablemente poco conveniente desde el punto de vista político. No podemos olvidar que el sistema europeo de protección de los derechos humanos se sustenta, en definitiva, en la voluntad de los Estados partes. Una interpretación excesivamente extensiva en la aplicación del Convenio, que vaya mucho más allá de donde los Estados parte han querido llegar por vía convencional, puede mermar la confianza de la comunidad de Estados miembros en el sistema, llegando a su desestabilización. Más aún si tenemos en cuenta que las resoluciones del Tribunal no son ejecutivas, sino meramente declarativas, en los ordenamientos internos. No en vano, en I973 el Gobierno alemán propuso la adopción de un Protocolo adicional al CEDH que contenía dos disposiciones: la proclamación del derecho a la salud, que conllevaba el derecho a no ser expuesto a cambios adversos en las condiciones naturales de vida que pudieran amenazar la salud o el bienestar personales; y la instauración de un procedimiento de reparación frente a los daños al medio ambiente provocados por los particulares. Esta iniciativa no encontró el cauce jurídico oportuno por falta de voluntad de los Estados, y desde entonces no se ha producido ninguna otra propuesta en ese sentido.

Con estas afirmaciones no quisiéramos incurrir en una visión conservadora del Convenio. Al contrario, hemos indicado que éste es, y debe ser, un instrumento vivo capaz de adaptarse a cada realidad histórica. Y, más aún, que el reconocimiento del derecho fundamental a un medio ambiente sano (y su efectiva aplicación) es una imperiosa necesidad ante la actual situación de degradación de los ecosistemas. Pero este deseo no debe impedir discernir con claridad hasta dónde han llegado hoy por hoy el TEDH y la Comisión, y más aún, hasta dónde les permite llegar el sistema de protección diseñado por el Consejo de Europa.

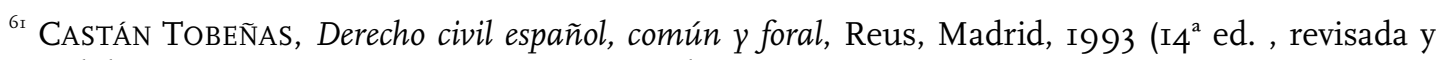
puesta al día por DE Los Mozos, J.L.), Tomo I, Vol. II, p. 32.
} 


\section{Algunas conclusiones sobre la acción del Tribunal y la Comisión en relación al medio ambiente: la ecologización de los derechos fundamentales.}

No cabe duda de que el Tribunal Europeo y la Comisión han emprendido un interesante camino para la protección del ambiente, teniendo en cuenta que el instrumento jurídico que vincula su actuación no contiene ninguna consideración al respecto de estos intereses. Asimismo, esta actuación, además de haber servido para amparar criterios de protección ambiental tanto individual como general, tiene el gran valor de haber puesto sobre la mesa de la doctrina internacional, con intensidad, la cuestión de la defensa jurídica del ambiente. Pero, frente a una lectura quizá excesivamente optimista de estos hechos, hemos advertido algunas importantes carencias en este sistema de protección, como: la consideración sólo parcial de las consecuencias de injerencias graves contra el ambiente, a partir de una insuficiente protección del derecho a la salud y la prohibición de tratos degradantes; la no consideración del principio de cautela, a través de una aplicación demasiado parca de medidas preventivas, y una interpretación restrictiva de las obligaciones positivas de los Estados parte en relación con el deber de información en materia ambiental; y una excesiva aplicación del párrafo segundo del artículo 8 como forma de priorización de supuestos intereses de economía nacional frente a la protección del ambiente, entre otras.

Si bien la reciente evolución de la jurisprudencia del TEDH y la Comisión parece dirigida a superar algunas de estas carencias, no podemos dejar de lado que, en realidad, las limitaciones de esta vía de protección derivan en buena parte de las propias características del sistema de protección derivado del CEDH. Irremediablemente -en tanto no se produzca una modificación del Convenio-, en este ámbito el medio ambiente será siempre protegido en aspectos marginales, ya que en realidad pocos atentados al entorno pueden ser alojados en la construcción realizada en el caso López Ostra; por el momento, sólo aquellos que sean reconducibles al ámbito protegido por el artículo $8 \mathrm{CEDH}$. A lo que hay que añadir los límites políticos, derivados de las características del Consejo de Europa como organización internacional, que acotan la actuación del TEDH y la Comisión.

Por otro lado, Jimena Quesada y Tomás Mallén han advertido algunas interrogantes y dificultades de tipo procesal. Refiriéndose, en concreto, al asunto López Ostra, y atendiendo al alcance inevitablemente colectivo de los daños ambientales, se han preguntado qué hubiese ocurrido si otros vecinos afectados por la planta depuradora hubiesen presentado demandas por el mismo hecho ante la Comisión, que podrían ser interpuestas de manera colectiva como grupo de particulares. Ante esta situación puede que la Comisión declarara inadmisibles las posteriores demandas por ser sustancialmente la misma que la anterior, o puede que, admitiéndolas, el TEDH se pronunciara sobre ellas de forma diferente. En ambos casos parece que se hubiese producido un trato discriminatorio. Estos problemas derivan nuevamente de la configuración individualista del CEDH, que hace que los cauces procesales para la protección del derecho al medio ambiente revistan serias dificultades de articulación, a causa de la naturaleza del propio bien jurídico medio ambiente y de sus múltiples facetas ${ }^{62}$. Además, hay que destacar que el mecanismo instaurado por el CEDH es siempre subsidiario, utilizable sólo cuando las autoridades nacionales no hayan conseguido reparar supuestas violaciones al Convenio en el ámbito interno. La prolongación de las injerencias que conlleva esta subsidiariedad, si bien puede ser más o menos grave, según los casos, desde el punto de vista de la preservación de derechos individuales, parece difícilmente admisible en relación a la protección ambiental, si consideramos el carácter irreparable de muchas de las agresiones al entorno.

La última carencia relevante que apuntaremos, derivada también de la propia configuración del sistema de protección europeo, hace referencia al hecho de que, como

\footnotetext{
${ }^{62}$ JimENA QUESADA Y TOMÁS MALLÉN, .op cit., p. $2 \mathrm{I} 64$.
} 
sucede en el asunto López Ostra, los atentados contra el ambiente proceden a menudo de actuaciones de particulares, normalmente empresas. Sin embargo, las únicas pretensiones que pueden esgrimirse ante el TEDH son aquéllas relacionadas con actuaciones de los poderes públicos. El Tribunal ha venido a reconocer la responsabilidad indirecta del Estado ante ciertas agresiones ambientales por omisión en la adopción de medidas conducentes a proteger a la ciudadanía frente a las mismas. Se trata de lo que la doctrina alemana ha denominado drittwirkung, o eficacia frente a terceros de las resoluciones del Tribunal. Sin duda es positiva la imputación de responsabilidad a los poderes públicos por la dejación de sus funciones en materia ambiental, pero hay que advertir que esta vía de protección supone, en definitiva, un descargo de responsabilidad para las empresas que, aunque causantes directas de la agresión al medio, no son destinatarias de la resolución (ni de la condena) del Tribunal. Por ello, el amparo otorgado por el TEDH y la Comisión puede llegar a ser contraproducente para la sensibilización ecológica de los agentes privados.

No obstante, y con todo lo dicho, no quisiéramos dejar de reconocer el valor de esta jurisprudencia ambiental. Es reseñable que el sistema compuesto por el TEDH y la Comisión es, con seguridad, la única sede judicial internacional que otorga una tutela semejante al medio ambiente, o al menos que manifiesta la voluntad de elevar los intereses ambientales a un lugar equiparable al del resto de derechos fundamentales.

Llegados a este punto debemos preguntarnos cuál es el mecanismo jurídico utilizado por el Tribunal y la Comisión para dar entrada a esos intereses ambientales en pie de igualdad con el resto de derechos fundamentales reconocidos por el Convenio, toda vez que descartamos el del reconocimiento de un derecho subjetivo de tipo ambiental. Por el contrario, lo que los órganos de Estrasburgo han venido efectuando a través de su jurisprudencia ambiental es una interpretación del conjunto del CEDH en clave ecológica, procediendo a una «ecologización» (greening, según su acepción anglosajona) de los derechos fundamentales ${ }^{6_{3}}$. Entendemos por tal una impregnación capilar y difusa de los criterios ecológicos en la aplicación del Convenio, es decir, una complementación del contenido de los derechos clásicos garantizados por el CEDH (por el momento de algunos de ellos) debido a la mayor concienciación y preocupación contemporánea por la protección del medio ambiente. Lo que, entendemos, tiene su base en el criterio hermenéutico denominado tradicionalmente en la doctrina española como sociológico: la interpretación de las normas de acuerdo con la realidad social del momento en que deben ser aplicadas.

Se trata, a nuestro juicio, de un enfoque adecuado, proporcionado a los medios al alcance del Tribunal y la Comisión, y de una considerable potencialidad de desarrollo futuro. Si manejamos un concepto amplio de ambiente, que incluya también la «tecnosfera» y la propia sociedad y cultura humanas, habremos de admitir que, en realidad, todo el ordenamiento jurídico -y por tanto todo el Convenio Europeo- recae sobre él. En consecuencia, Gordillo Ferré ha suscrito la necesidad de una «ecologización» de todo el ordenamiento jurídico, paralelamente a una «ecologización» de la política, de la economía y de la cultura ${ }^{64}$.

Un enfoque adecuado, pero insuficiente en el caso del CEDH. Por un lado porque la labor interpretativa del Tribunal y la Comisión, aun circunscrita básicamente al artículo 8 , precisa de un mayor desarrollo ${ }^{65}$. Por otro, porque la protección del ambiente siempre

\footnotetext{
${ }^{6}$ Esta opinión es sostenida, entre otros, por GARCÍA SAN JOSÉ, D., op. cit., p. I2II.

${ }^{64}$ Vid. GORDILLO FERRÉ, J.L., «Del Derecho ambiental a la ecologización del Derecho», en VV.AA., transformaciones del Derecho en la Mundialización, Escuela Judicial (CGPJ), Madrid: 2000, p. 328 y ss.

${ }^{65}$ Según GARCía SAN José, D., op. cit., p. I2II., la labor emprendida por el TEDH exige un doble desarrollo: horizontal, mediante la consideración de otros derechos del Convenio como susceptibles de resultar violados a consecuencia de un ataque medioambiental; y, al mismo tiempo, vertical,
} 
resultará insuficiente si se considera desde derechos estrictamente individuales. Por ello, junto con esa «ecologización» del conjunto del Convenio, el cauce más ortodoxo para la defensa del ambiente sería su reconocimiento expreso como derecho fundamental a través de un Protocolo adicional al CEDH.

\section{Bibliografía.}

BASSOlS COMA, M., «Propiedad privada y cuestiones de medio ambiente», en BARNÉS, J. (coord.), Propiedad, expropiación y responsabilidad. La garantía indemnizatoria en el derecho europeo y comparado, Madrid: Tecnos y Junta de Andalucía, I996, p. 727 a 754.

BOUAZZA ARIÑO, O., «Respeto a la vida privada y protección del medio ambiente en la jurisprudencia del Tribunal Europeo de Derechos Humanos», Revista de Administración pública, I6o, enero-abril 2003, p. I67 a 202

CARrillo Donaire, J.A., y Galan Vioque, R., «¿Hacia un derecho fundamental a un medio ambiente adecuado? (Comentario en torno al asunto López Ostra c. España, resuelto por la sentencia del Tribunal Europeo de Derechos Humanos de 9 de diciembre de i994)», REDA, 86, abril-junio I995, p. 27I a 285.

Francione, G.L., Animals, property, and the law, Philadelphia: Temple University Press, 1995.

GARCíA SAN JOSÉ, D., «Derecho al medio ambiente y respeto a la vida privada y familiar (Comentario a al STEDH de 9 de diciembre de I994)», La Ley, 4, I995, p. II95 a I2I3.

Georgescu-Roegen, N., La Ley de la Entropía y el Proceso Económico, Fundación Argentaria, Madrid: 1996.

GONZÁLEZ-VARAS IBÁÑEZ, S., «El ruido de los aeropuertos: el aeropuerto de Heathrow y la condena al Estado británico (La sentencia de 2 de octubre de 200 I del Tribunal Europeo de Derechos Humanos)», TC, enero 2002, p. 27 a 56.

tomando una mayor conciencia del derecho al disfrute de los bienes y al respeto del bienestar en la esfera del domicilio privado, como implícito en el sistema de derechos garantizados por el Convenio. Por su parte, Melchor ha realizado un estudio sobre las posibles vías extensión de los derechos reconocidos por el Convenio como vía para la protección de otros no reconocidos en el mismo, algunas de las cuales pueden resultar de interés para el tema que nos ocupa. Vid. MELCHOR, M., «Rights not covered by de Convention», en MCDonAld, R.St.J., MATSCHER, F. y PETZOLD, H. (eds.), The European System for de Protection of Human Rights, Kluwer Academic Publishers, Dordrecht: I993, p. 593 a 6or. De indudable interés resulta el estudio realizado por Doorduijn sobre las posibilidades específicas de protección del medio ambiente en el CEDH, apoyándose en un gran número de disposiciones convencionales: artículos 2 (derecho a la vida), 3 (prohibición de tratos inhumanos y degradantes), 6 (derecho a un proceso justo), 8 (derecho al respeto de la vida privada y familiar y del domicilio), io (libertad de expresión y de información), i3 (derecho a un recurso efectivo ante una instancia nacional), I4 (prohibición de discriminación), , y 2 del Protocolo adicional núm. I (derecho al goce pacífico de la propiedad y al respeto de sus bienes y derecho a la instrucción, respectivamente) y 2 del Protocolo adicional núm. 4 (libertad de movimientos y de residencia). Vid. DOORDUIJN, N., Towards a «green» interpretation of the European Convention on Human Rights? Possibilities and impossibilities for enviromental protection under the European Convention on Human Rights, Ginebra: 1994 (citado por JIMENA QuesADA, L. y TOMÁs MALLÉN, B.S., op. cit., p. 2155 y ss.). 
GORDILlo FERRÉ, J.L., «Del Derecho ambiental a la ecologización del Derecho», en VV.AA., transformaciones del Derecho en la Mundialización, Escuela Judicial (CGPJ), Madrid: 2000, p. 307 a 340.

HUELIN MARTínez De VelASCO, J., «Intimidad personal y familiar, domicilio y medio ambiente», en VV.AA., Perfiles del derecho constitucional a la vida privada y familiar, Madrid: Escuela Judicial/CGPJ, I996, p. 257 a 274.

JIMENA QUESADA , L. y TOMÁS MALLÉN, B.S., «El derecho al medio ambiente en el marco del Convenio Europeo de Derechos Humanos», Revista general de derecho, 6I8, I996, p. $2 \mathrm{I} 35$ a $2 \mathrm{I} 79$.

JoRdANO FRAGA, J., La protección del derecho a un medio ambiente adecuado, Barcelona: Bosch, I995.

- «El derecho a disfrutar de un medio ambiente adecuado es un derecho subjetivo», en VV.AA., I Congreso Nacional de Derecho Ambiental, Sevilla, abril 1995, Valencia: Cima Medio Ambiente, I996, p. 455 a 462.

LozANo CuTANDA, B., «La ecologización de los derechos fundamentales: la doctrina López OSTRA c. España, Guerra y otros c. Italia y Hatton y otros c. Reino Unido del TEDH y su recepción por nuestro TC», REDE, I, 2002, p. I75 a 205.

MARTÍN MATEO, R., «Avances en la efectividad de la responsabilidad ambiental», en Moreno MARTínez (coord.), Perfiles de la responsabilidad civil en el nuevo milenio, Madrid: Dykinson, 2000, p. 223 a 234.

MARTín-Retortillo BAquer, L. «La defensa frente al ruido en el Tribunal Constitucional (Auto de I3 de octubre de I987, en relación con la clausura de un bar en Sevilla)», Revista de Administración Pública, II5, I988, p. 205 a 23I

- «El ruido en la reciente jurisprudencia», Revista de Administración Pública, I25, I99I, p. 319 a 342

- $\quad$ «Influencia de la jurisprudencia del Tribunal Europeo de Derechos Humanos en la del Tribunal Constitucional», en Jurisprudencia del Tribunal Europeo de Derechos Humanos II, Cuadernos de Derecho Judicial, Madrid: CGPJ, abril de I995, p. 263 a 287 .

- $\quad$ «El ruido de los grandes aeropuertos en la jurisprudencia del Tribunal Europeo de Derechos Humanos», en VV.AA., Derecho del medio ambiente, Madrid: Centro de Estudios Jurídicos de la Administración de Justicia, I995, p. II5 a I38.

- «Medio ambiente sonoro», en EsteVe PARdo (dir.), Derecho del Medio Ambiente y Administración Local, Madrid: Cívitas y Diputació de Barcelona, I996, p 227 a 26I

MARTínez De PisÓn CAVERo, J., El derecho a la intimidad en la jurisprudencia constitucional, Madrid: Civitas, I992.

MATIES GARCÍA, J., «La responsabilidad civil en los suelos contaminados», en VV.AA., I Congreso Nacional de Derecho Ambiental, Sevilla, abril 1995, Valencia: Cima Medio Ambiente, I996, p. 455 a 462. 
MELCHOR, M., «Rights not covered by de Convention», en McDONALD, R.St.J., MATSCHER, F. y PETZOLD, H. (eds.), The European System for de Protection of Human Rights, Kluwer Academic Publishers, Dordrecht: I993, p. 593 a GoI.

Mosterín, J. y Riechmann, J., Animales y ciudadanos. Indagación sobre el lugar de los animales en la moral y el derecho de la sociedades industrializadas, Madrid: Talasa, I995.

NAVARro Gómez, C., «La protección del medio ambiente en el marco del Convenio Europeo de Derechos Humanos», en VV.AA., I Congreso Nacional de Derecho Ambiental, Sevilla, abril 1995, Valencia: Cima Medio Ambiente, I996, p. 201 a 206.

PABlo JimÉnEZ, E., Los derechos humanos de la Tercera Generación, Buenos Aires: EIDAR, 1997.

PÉREZ LUÑo, A.E., «Estado constitucional y derechos de la tercera generación», Anuario de filosofía del derecho, 13-14, 1996-1997, p. 545 a 570.

RiECHMANN, J. «Desarrollo sostenible: la lucha por la interpretación», en VV.AA., De la economía a la ecología, Madrid: Trotta y Fundación I de Mayo, I995, p. in a 36.

RodRíGUEZ RUIZ DE VILLA, D., «La protección jurídica indirecta del medio ambiente», La Ley: Revista jurídica española de doctrina, jurisprudencia y bibliografía, 3, I992, p. 880 a 9I4.

RUIZ Rico, G., El derecho constitucional al medio ambiente (dimensión jurisdiccional), Valencia: Tirant lo Blanch, 2000.

SÁNCHEZ FÉRRIZ, R., Estudio sobre las libertades, Valencia: Tirant lo Blanch, I989.

SUDRE, F., «Chronique de la jurisprudence de la Cour européenne des droits de l'homme I994", Revue Universelle des Droits de l'Homme, vol. 7, 4-6, junio de I995.

Velasco Caballero, F. «Protección del medio ambiente ante el Tribunal Europeo de Derechos Humanos», Revista Española de Derecho Constitucional, 45, septiembre I995, p. 305 a 324 .

- La vinculación negativa del legislador a los derechos fundamentales, Madrid: McGrawHill, I996.

VerCher Noguera, A., «Consejo de Europa y protección penal del medio ambiente», La ley: Revista jurídica española de doctrina, jurisprudencia y bibliografía, 2, I99I, p. I070 a IO8I. 